\title{
Hybrid model for exhaust systems in vehicle thermal management simulations
}

\author{
Saad Ahmed ${ }^{1}$ (i) $\cdot$ Hermann Rottengruber ${ }^{2} \cdot$ Markus Full $^{2}$
}

Received: 27 October 2021 / Accepted: 10 February 2022 / Published online: 25 February 2022

(c) The Author(s) 2022

\begin{abstract}
Using Vehicle Thermal Management (VTM) simulations to predict the thermal load experienced by components is a popular method within the automotive industry. The VTM simulation approach is fast becoming equivalent to conducting thermal load tests with prototypes for vehicles powered by internal combustion engines. This is especially true in the early development phase of the vehicle. The accuracy of the VTM simulations plays a pivotal role at them being accepted as an eventual replacement for physical testing. The correct prediction of thermal loads in VTM simulations depends on a multitude of different parameters, but the modelling of the exhaust system plays a central role in it. This is because the exhaust gas, and with it the exhaust system, is the primary source of heat in a vehicle powered by an internal combustion engine. The developed approach not only needs to be accurate but also modular enough to allow for different exhaust configurations to be tested. It also needs to be capable of integration into any VTM simulation workflow while maintaining an industrially acceptable turnaround time. This paper explores a new methodology to achieve these requirements. A 1D/3D hybrid approach to exhaust system modelling is presented. In this, the components that have an enthalpy change of the exhaust gas, such as the turbocharger, have been modelled as 1D and simple components such as pipes have been modelled in 3D. This has the advantage of combining the speed of 1D simulations with the spatial accuracy of 3D simulations. The method uses a unique three-code co-simulation technique for full vehicle VTM simulations. The coupling is between a 3D CFD software, a 1D simulation tool, and a Finite Element based thermal solver. The methodology was validated against experimental data for multiple loadcases. The results show good agreement with experiment within acceptable tolerances.
\end{abstract}

Keywords VTM simulations $\cdot$ Exhaust system $\cdot$ Thermal safety $\cdot$ Heat transfer $\cdot$ 1D/3D method $\cdot$ CFD $\cdot$ Co-simulation $~$ 3 -code coupling $\cdot$ Thermal mass modelling $\cdot \mathrm{B} 60 \cdot \mathrm{Vmax} \cdot$ Thermography $\cdot$ Dynamic potential

\section{Abbreviations}

1-D One-dimensional

3-D Three-dimensional

B60 Steady state uphill at $60 \mathrm{~km} / \mathrm{h}$

BMW Bayerische Motoren Werke

CFD Computational fluid dynamics

EAS End acoustic silencer

HTC Heat transfer coefficient

Saad Ahmed

saad.ahmed@bmw.de

Hermann Rottengruber

hermann.rottengruber@ovgu.de

Markus Full

markus.full@bmw.de

1 BMW Group, Munich, Germany

2 Institute of Mobile Systems (IMS), Otto von Guericke University Magdeburg, Magdeburg, Germany
MAS Middle acoustic silencer

PCC Primary catalytic converter

RLT Result variable in GT-power

RMS Root mean square

RPM Revolutions per minute

MRF Moving reference frame

RBM Rigid body motion

UDMS User defined momentum source

AUDMS Augmented user defined momentum source

SCC Secondary catalytic converter

Tfluid Fluid temperature

TMM Thermal mass modelling

Vmax Maximum vehicle velocity

VTM Vehicle thermal management

List of symbols

$C_{f} \quad$ Fanning friction factor

$R e_{D} \quad$ Reynold's number

$\dot{m} \quad$ Mass flow rate 


$\begin{array}{ll}\eta & \text { Isentropic efficiency } \\ \dot{Q} & \text { Rate of heat transfer } \\ \Delta h & \text { Instantaneous enthalpy drop in the turbine } \\ \chi & \text { User-defined factor } \\ C_{\mathrm{th}} & \text { Thermal mass } \\ m & \text { Mass } \\ c_{p} & \text { Specific heat capacity } \\ h_{\text {custom }} & \text { Custom heat transfer coefficient } \\ \vec{\Phi}_{\mathrm{q}} & \text { Heat flux } \\ T_{\text {iso }} & \text { Fluid temperature value at iso-surface } \\ T_{s} & \text { Temperature at pipe surface }\end{array}$

\section{Introduction}

In a vehicle with a conventional internal combustion engine, the efficient management of waste heat is of utmost importance to ensure thermal protection of components. This is all the more relevant in the early stages of vehicle development so as to avoid costly changes further down the developmental chain. In recent times, stricter emission regulations for combustion engines have lead to more after treatment components being added inside the vehicle. This has lead to tighter packaging in and around the engine bay area. All of this has made thermal protection inside of a modern combustion engine vehicle much more critical than in the past.

Traditionally, to ensure the thermal integrity of a vehicle, different experiments are performed under specific load conditions. These experiments are undertaken either in a climatic windtunnel or out on the street. The experimental approach to thermal management has been proven to be highly reliable. However, it has a dependency on hardware prototypes that are usually only available in later stages of development. In a bid to remove this dependency and to ensure thermal protection much earlier in a vehicle's development, a virtual approach to thermal management is being fast adopted across the automotive industry. This is done via the use of Vehicle Thermal Management (VTM) simulations. The simulations can be used as a complimentary approach to the experiments initially and may also serve to be an eventual replacement of the experimental approach.

VTM simulations can be performed in one of two ways: (1) Conjugate Heat Transfer simulations or (2) Co-simulations. The first approach involves solving all of the heat transfer equations in a single solver. In Co-simulation, convection is solved using a CFD code and the two other heat transfer mechanisms are solved using a separate thermal solver. The methodology for exhaust system simulations proposed in this paper has been developed to be used in a Co-simulation approach.

In order for the simulative approach to be as reliable and accurate as the experimental approach, all the sub-systems of the vehicle need to be accurately modelled. As the exhaust system is the primary emitter of waste heat into the vehicle, the accuracy in its modelling is imperative to the accuracy of the simulative approach. Multiple methodologies for the simulation of the exhaust system have been developed over the years. These are mentioned in the following section. In the Methodology section, a unique approach to exhaust system simulation is proposed. The validation of this proposed methodology is shown in the Results section.

\section{State of the art}

As mentioned previously, the exhaust system is the primary contributor of waste heat inside a vehicle. It affects the components in its vicinity by direct radiation. The system also rejects a lot of heat via convection and this leads to convective heating in other areas of the vehicle. All of this makes exhaust system modelling an integral part of VTM simulations. As the VTM simulations first started gaining popularity, the method to simulate the exhaust systems was by holding them at a constant surface temperature. The value for these surface temperatures was obtained from experimental data. The biggest drawback of this approach was that the measurements would usually be retrieved from a single point and then applied to the entire surface of the exhaust component. This misrepresents the temperature gradient on the surface of the component. The surface temperatures are then miscalculated in simulation which leads to an inaccurate heat input into the components surrounding the exhaust system.

For this reason, methodologies that would predict rather than fix the exhaust system temperatures were developed. Zhang et al. were the first ones to calculate exhaust surface temperatures with the help of computer modelling. Their approach incorporated a custom algorithm that calculated the basic heat transfer equations inside the exhaust system [39]. Currently, most of the methodologies for modelling the exhaust system can be divided into one of two categories: (1) A completely 3-D approach or (2) A completely 1-D approach. A completely 3-D approach that is integrated into a full vehicle Co-simulation workflow can be complex and lead to higher turnaround times. This is especially true when trying to model complex components, such as turbochargers and catalytic converters. However, there have been a number of attempts at this approach. Enriquez-Geppert proposed a methodology that could simulate the complete exhaust system in 3-D, including the influence of the surrounding vehicle geometry [6, 7]. The methodology uses a 3-D CFD code for both internal and external flow calculations. The aftertreatment devices were modelled using a 1-D code separately and the results were integrated into the 3-D modelling. The results achieved by the methodology were promising. A fully 1-D methodology for simulating the exhaust system 
was proposed by Haehndel [14]. This approach involved splitting the exhaust system into a series of pipes and applying custom Heat Transfer Coefficients (HTC) to each of the pipes. The calculation of the heat transfer coefficients was done based on 1-D Nusselt correlations. These HTC values were then applied to the inner surface of the pipe sections in a thermal solver $[16,17]$.

The approach was further developed by Heinemann [21] by incorporating the exothermic reaction in the catalytic converter. This was done using a correlation to augment the exhaust gas temperatures inside the catalytic converter based on experimental data. Schlipf improved the method further by including the heat transfer effects inside an acoustic silencer [31]. The results showed good resolution of the local thermal gradients on the surface of the acoustic silencers [18]. The methodology was advanced further by DeVos via the development of a process to calculate the heat rate augmentation within the turbocharger system [34]. This was done using Dean and Nusselt correlations for vortices in centripetal flow domains. In addition to the 1D and 3D methodologies mentioned above, there has also been research on developing a 1D/3D hybrid model [29, 30], but this was limited to a few sub-systems of the exhaust. Apart from the simulation of the complete exhaust system, there have been numerous studies on the thermal behavior of exhaust aftertreatment components, such as the catalytic converters [2, $4,11,12,19,20,23,37]$.

\section{Setup}

The methodology proposed in this paper was validated against experimental data. All the experiments were performed inside an environmental windtunnel. A total of 110 measurement probes were setup across the vehicle to measure surface and fluid temperatures. Of these 46 measurement probes were set directly onto the exhaust system. The probes used were type $\mathrm{K}$ thermocouples. Figures 1 and 2 show some of the measurement probes attached to exhaust manifold

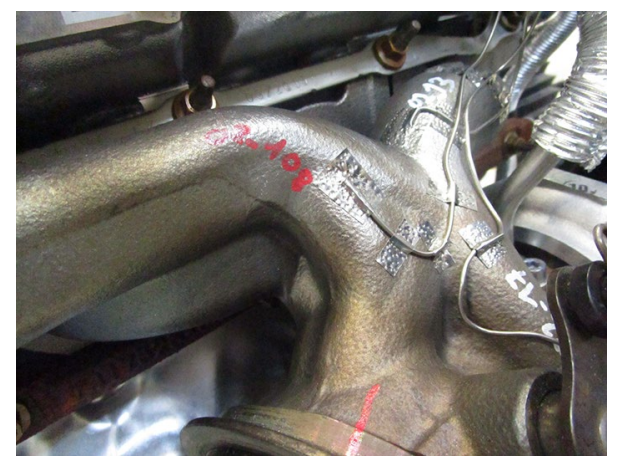

Fig. 1 Measurement thermocouples attached to the exhaust manifold

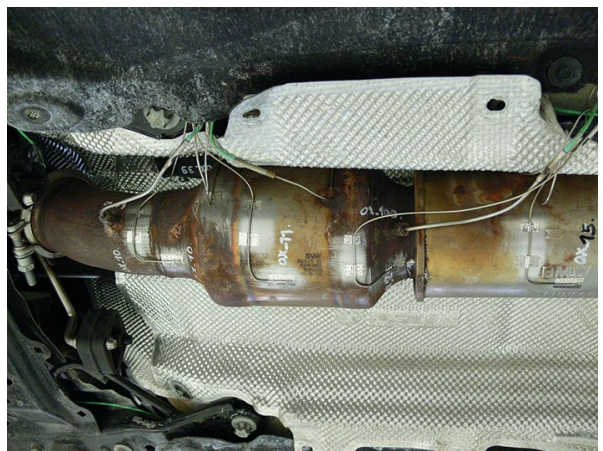

Fig. 2 Measurement thermocouples attached to the exhaust components along with fluid measurement probes inserted into the pipe

assembly and further downstream on the Middle Acoustic Silencer (MAS) and Secondary Catalytic Converter (SCC). In addition to using the thermocouples to measure surface and fluid temperatures, infrared cameras were used to record the surface temperature gradients using Thermography. This provided a qualitative assessment of the simulation results.

To evaluate the exhaust system, experiments from two loadcases were used. They are:

(a) Constant uphill drive at $60 \mathrm{~km} / \mathrm{h}$ with a gradient of 10 percent. The outside temperature is set to $35^{\circ} \mathrm{C}$. This will be referred to as B60 in the rest of the paper.

(b) Constant highway driving at the maximum vehicle velocity. The outside temperature is set to $45^{\circ} \mathrm{C}$. This will be referred to as Vmax in the rest of the paper.

\subsection{Simulation setup}

Both a 3D and 1D flow solver were used in the modelling of the flow of the exhaust gases in the exhaust system. Each of these were then coupled with a Finite Element based thermal solver that modelled the inner and outer surfaces of the exhaust system. For the purposes of this paper, only the methodologies developed in the 3D and 1D code are relevant. This section gives an overview of the simulation setup in both of those codes. The simulation setup for the 3D CFD code used has been summarised in Table 1 .

Table 2 gives an overview of the 1D setup.

\section{Methodology}

As mentioned previously, the exhaust system is the primary emitter of heat into the vehicle and with tighter packaging, its influence on the temperatures of neighbouring components is significant. Hence, accurate modelling of the exhaust system is of utmost importance in VTM simulations. 
Table 1 3D simulation setup

\begin{tabular}{ll}
\hline CFD code & Star-CCM+ Ver.12.02.010 \\
Number of volume cells for heat exchanger-submodel & 12 Million \\
Number of volume cells for full vehicle model & 38 Million \\
Solver setup: momentum & Segregated flow \\
Solver setup: energy & Segregated fluid temperature \\
Turbulence model & Realizable k- $\epsilon$ \\
Flow type & Incompressible ideal gas \\
Number of iterations for steady state simulations & 6000 \\
Time step size for transient simulations & $5 \times 10^{-4}$ s \\
Fan modelling & MRF,RBM,UDMS and AUDMS \\
Heat exchanger modelling & Dual-stream with UAG table \\
\hline
\end{tabular}

Table 2 1D simulation setup

\begin{tabular}{ll}
\hline 1D code & GT-Power Ver. 2018.3 \\
Fluid solution & Unsteady \\
Temporal integration scheme & Explicit Runge-Kutta \\
Thermal solution & Steady \\
Heat transfer correlation & Dittus Boelter \\
Time step size & Automatic \\
Convergence tolerance & Fractional mass flow \\
& rate change of 0.002 \\
\hline
\end{tabular}

There have been various attempts in the past to model the exhaust system temperatures in a complete vehicle model $[3,5,6,8,9,15,22,25-28,33,38,39]$. Although, the results of these methods are promising, they have potential for improvement in terms of modularity. The methodology proposed in this study aims at modelling the exhaust system as a hybrid combination of $1 \mathrm{D}$ and $3 \mathrm{D}$ approaches. In this, the entire exhaust system is divided into different groups of components. These groups are then modelled with a 1D or a 3D approach. The different groups are then connected via a coupling tool to efficiently exchange information at their interfaces. Components such as the turbocharger or the catalytic converters which augment the heat energy inside the exhaust gas will be modelled in 1D. This reduces the complexity in modelling such components while still maintaining their influence on the exhaust gas. Simpler components such as the exhaust pipes will be modelled in 3D. This helps in capturing complex 3D effects such as bend and entrance effects inside the exhaust system piping. The hybrid approach also has the advantage of coupling the speed and response of 1D modelling with the spatial accuracy of 3D modelling. It also has the advantage of being a modular approach, where different layouts of the exhaust system can be tested quickly.

The execution of the modelling of the exhaust system was done in three phases. The first phase involved modelling the entire system in 3D. This served the purpose of establishing a baseline spatial accuracy for the entire study. It also highlighted the challenges of modelling components, such as the turbocharger in 3D. For the second phase of the modelling, a fully 1D approach was developed for the exhaust system. The spatial accuracy and turnaround time for this phase served as a comparison to those of the completely $3 \mathrm{D}$ approach. In the third and final phase of the development, the hybrid model for the exhaust system was developed. The modelling in this phase was an attempt to combine the advantages of the previous two phases.

\subsection{Complete 3D}

The vehicle chosen for this study was the MINI Clubman JCW. It uses an inline 4-cylinder turbo-charged petrol engine. The exhaust system of the vehicle is shown in Fig. 3. It consists of a single turbocharger, two catalytic converters and two acoustic silencers.

For the purposes of this paper, all the components up to the Primary Catalytic Converter (PCC) will be classified together as the hot-end of the exhaust system. The components downstream from this point will be denoted as the cold-end. The flow of the exhaust gas coming out of the exhaust valves is pulsating. The effect of pulsation on the heat transfer coefficients is highest in the components closest to the exhaust valves, i.e., the hot-end [15]. To accurately capture this effect, a submodel of the hot-end of the exhaust system was separately simulated under transient boundary conditions. The submodel is shown in Fig. 4.

The boundary conditions used for the exhaust gas pulses in the submodel are given in the form of inlet curves for mass flow rate and total temperature. Total temperature is defined as in Eq. 1. The inlet curves are shown in Fig. 5.

$T_{t}=T+\frac{v^{2}}{c_{p}}$

where

$T_{\mathrm{t}}$ is the total temperature in $\mathrm{K}$ 
Fig. 3 Complete exhaust system of the MINI Clubman JCW

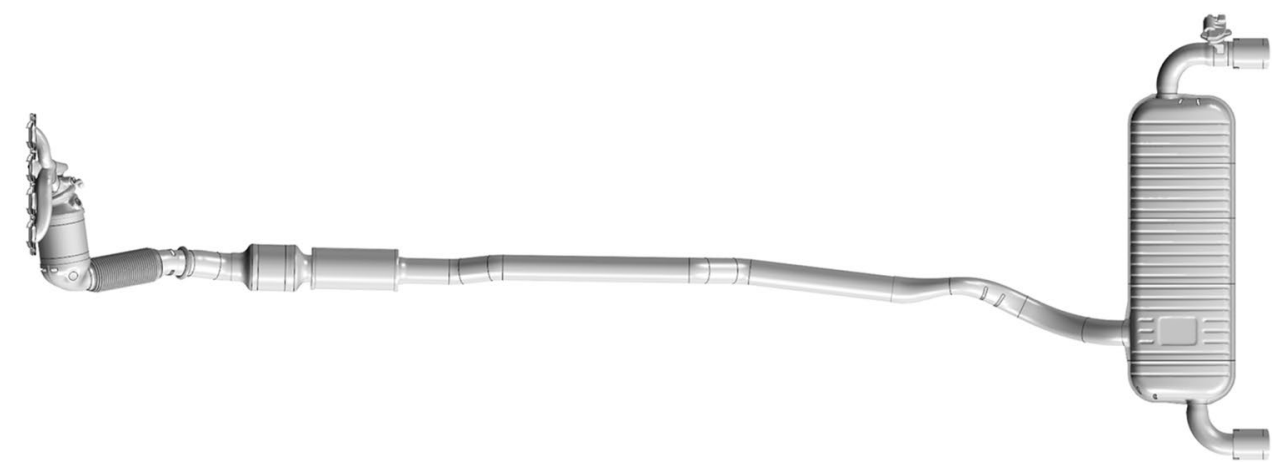

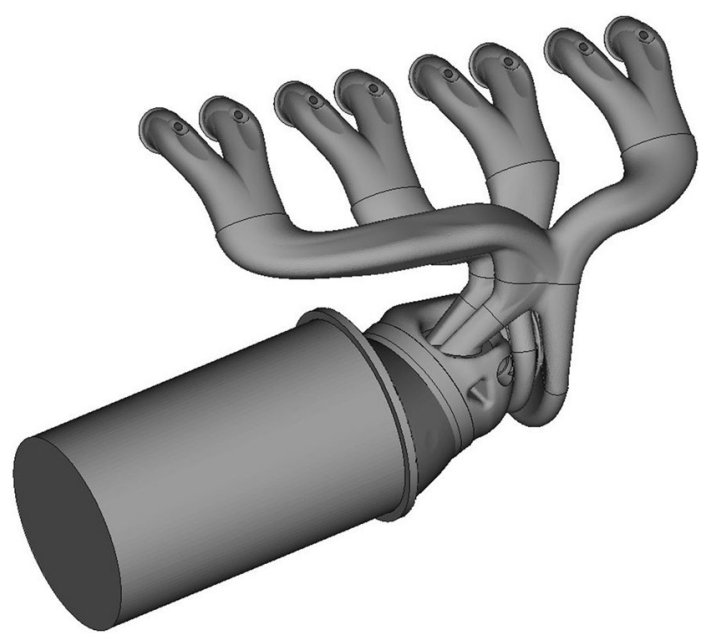

Fig. 4 Hot-end submodel

$T$ is the static temperature in $\mathrm{K}$

$v$ is the velocity of the medium in $\mathrm{m} / \mathrm{s}$

$c_{\mathrm{p}}$ is the specific heat capacity in $\mathrm{J} / \mathrm{kg} \cdot \mathrm{K}$

RMS values of the exhaust gas temperatures and heat transfer coefficients were then exported from the submodel and mapped onto the inner walls of the hot-end of the complete 3D model inside the 3D CFD code. These values were held constant over the course of the simulation. The corresponding values for the cold-end were calculated inside the 3D CFD code. A mass flow inlet was set up at the exit of the PCC, the boundary conditions for which were also imported from the submodel. The whole simulation inside 3D CFD code was run under steady state conditions.

The primary catalytic converter (PCC) and the secondary catalytic converter (SCC) were modelled as a porous region. The porosity was set to be homogenous throughout the volume and this value was determined using pressure measurements upstream and downstream of the catalytic converter. To model the exothermic reaction caused by catalysis, a constant volumetric heat rate was added. To calculate this value, first the fluid temperature values upstream and downstream of the catalytic converters were taken from experiment. The volumetric heat rate was then
Inlet Boundary Conditions - B60

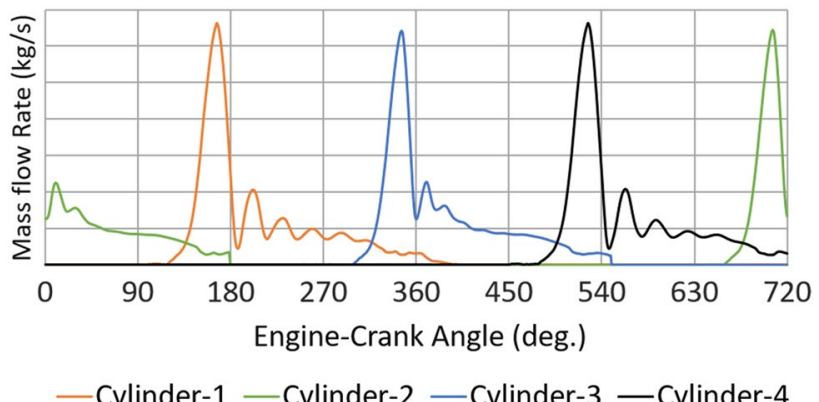

Inlet Boundary Conditions - B60

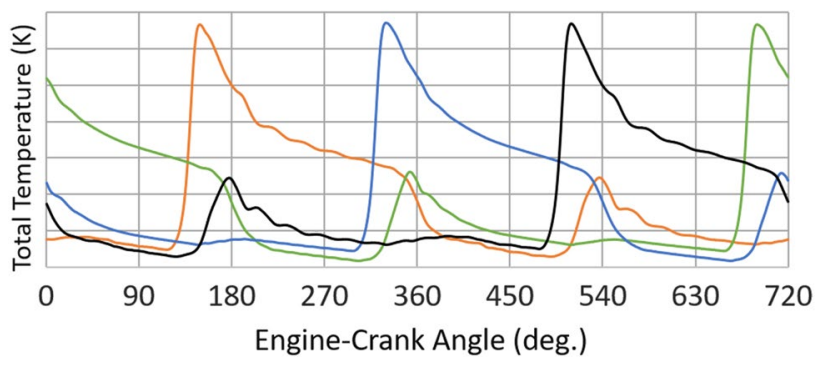

- Cylinder-1 - Cylinder-2 - Cylinder-3 - Cylinder-4

Fig. 5 Inlet boundary conditions for mass flow rate and total temperature provided to the $1 \mathrm{D}$ model

calculated based on the difference of the two temperature values and the mass flow rate through the catalytic converter. The reliance on experimental values to correctly model the catalytic converters and the assumptions for constant heat addition and homogenous porosities add to the complexity of modelling these components in 3D.

The Middle Acoustic Silencer (MAS) and End Acoustic Silencer (EAS) were modelled in the entirety of their internal structures. This is shown in Fig. 6. The perforated pipes are surrounded by a porous sound-dampening material known as Glasswool. To effectively model the porous effect of this material, a porous resistance was added to the 
Fig. 6 Inner structure of the MAS (Left) and the EAS (Right)

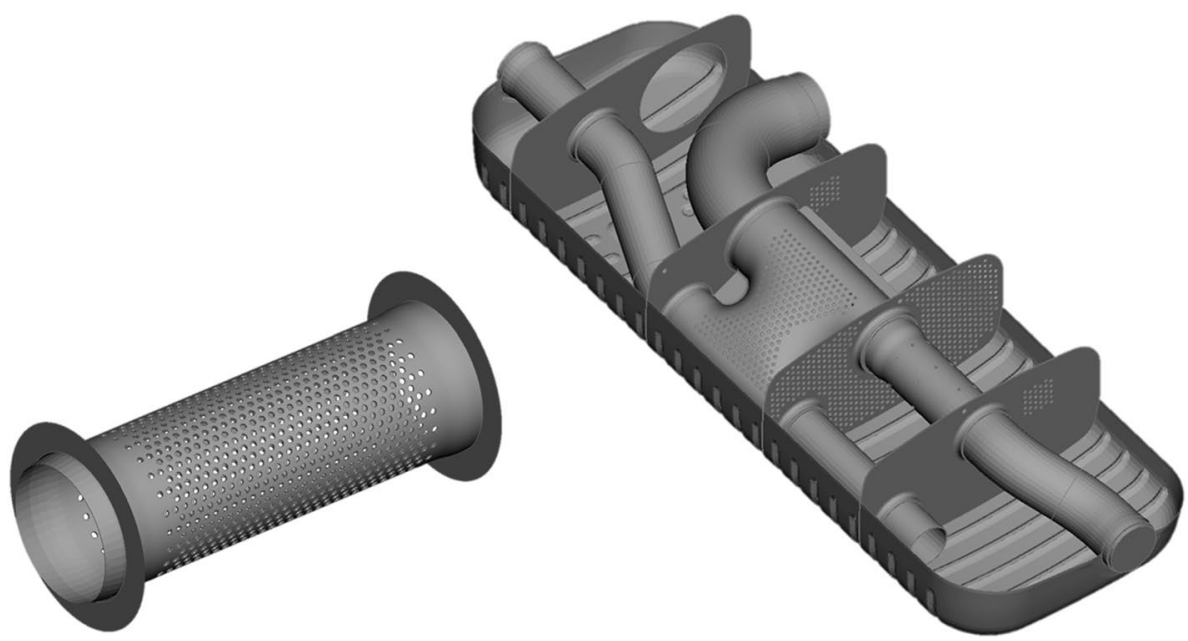

hole interfaces inside the pipes. The value for this resistance was obtained from experiment.

The method for exporting the HTC values inside the 3D CFD code for this approach exports the values from the first cell vertex close to the wall. An inherent drawback of this method is the inconsistency in the HTC values that are exported. This is because of variability in the mesh density and distribution inside the exhaust pipes. This inconsistency has an effect on the accuracy of the completely 3D approach. This is discussed further in the results section of the paper. To overcome this drawback, a new custom approach was introduced for the hybrid modelling of the exhaust system. This is discussed in a subsequent sub-section of the paper.

The 3D model of the exhaust system was then integrated into the full vehicle model for VTM simulations. After running some initial simulations, it was noted that the hot-end of the exhaust system was returning surface temperature values that were significantly lower than the experiment. A subsequent analysis to find the cause of this discrepancy revealed that the HTC and fluid temperature values being mapped to the 3D CFD code were quite low. The reason for this was found to be the assumptions and formulations made in hot-end sub-model simulations. To correct this, the approach for modelling the hot-end inside the 3D model was altered. Mass flow inlets were set for each of the primary pipes of the exhaust manifold. Mass flow values averaged over the entire engine cycle were used as the inlet values. Temperature values for the inlet were set to use mass flow averaged values of the total temperatures from Fig. 5. To model the effect of the turbocharger assembly in 3D, the forces of the turbine acting on the exhaust gas was exported from the submodel. These forces were then used inside the 3D CFD code to model the rotating turbine, as shown in Fig. 7. The technique used is similar to the one introduced in [1] to model a rotating fan.

Modelling the exhaust system with this revised approach reduced the complexity of having to map the values from the sub-model and improved the surface temperature values on the hot-end. However, it did increase the complexity of having to model the turbocharger in the completely $3 \mathrm{D}$ approach.
Fig. 7 Modelling of the turbine using UDMS

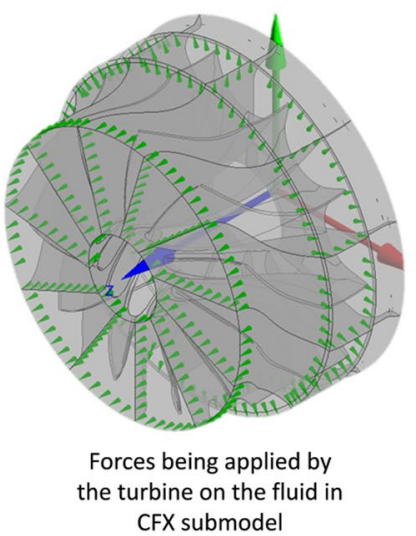

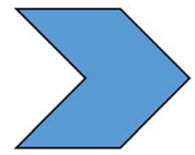

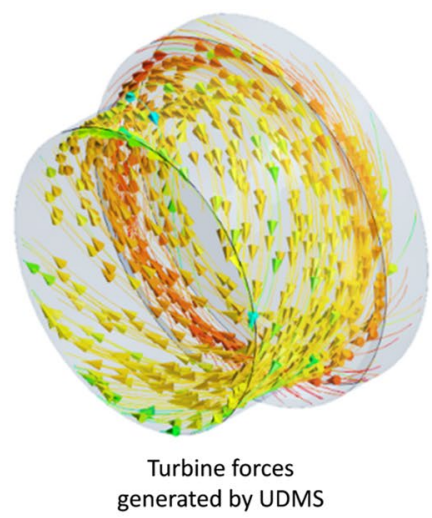




\subsection{Complete 1D}

In the second phase of development of the exhaust model, the entire system was modelled in 1D.

The following boundary conditions were provided as an input to the 1D model:
(a) Inlet mass flow and total temperature values
(b) Engine RPM
(c) Exhaust gas composition
(d) Turbocharger RPM and performance map

The same data for the input conditions was used, as shown earlier in Fig. 5. As the simulation was run under transient conditions, no additional averaging of the data was required.

The modelling of the exhaust system in 1D can be split into four broad sections:
(a) The piping network
(b) The turbocharger
(c) The catalytic converters and middle acoustic silencer
(d) The end acoustic silencer

The network of pipes of the exhaust system can further divided into multiple sections. These would be:
(a) Exhaust manifold
(b) Piping between the turbocharger and the PCC
(c) Piping between the PCC and SCC
(d) Pipe joining SCC and MAS
(e) Piping between MAS and EAS
(f) Internal pipes of EAS
(g) Tail-pipes

All of the sections mentioned above were modelled using the standard pipe and flow objects included in the 1D code. All of the geometrical variations such as varying diameters and bends in the pipe sections were accounted for using various inbuilt correlations in the code. Losses due to friction were incorporated using the Fanning friction factor [10]. This is shown in Eq. 2. The HTC values for the pipes were calculated using the Dittus Boelter correlation shown in Eq. 3. These values were then exported to the thermal solver which solves for the wall temperatures. The 1D code then receives these wall temperature values and uses them as a boundary condition at the pipe wall for the next iteration:

$C_{f}=\frac{16}{R e_{D}}$

where

$C_{f}$ is the Fanning friction factor

$R e_{D}$ is the Reynolds number

$N u=0.023 \operatorname{Re}^{0.8} \operatorname{Pr}^{n}$

where

$\mathrm{Nu}$ is the Nusselt number

Re is the Reynolds number

Pr is the Prandtl number

$\mathrm{n}$ is a factor that equals 0.4 when the fluid is receiving heat from the surface and 0.3 when the fluid is losing heat to the surface

Figure 8 shows the internal surface of the exhaust manifold geometry and the corresponding $1 \mathrm{D}$ modelling in the $1 \mathrm{D}$ code.

As shown in Fig. 8, the manifold has been geometrically split into multiple sections. This was done to discretise the complex manifold geometry into the 1D flow objects
Fig. 8 Modelling of exhaust manifold inside the $1 \mathrm{D}$ code

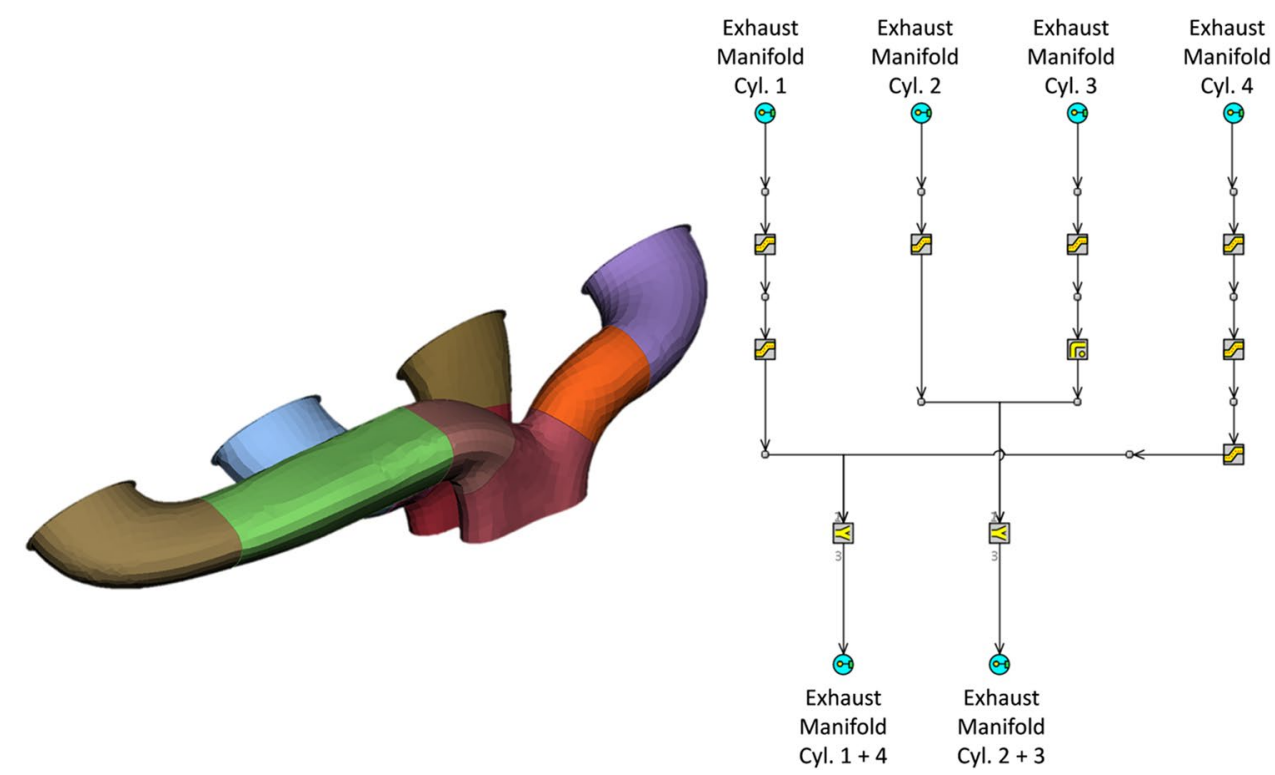


mentioned earlier. The rest of the exhaust piping network is similarly discretised.

For every pipe object in the 1D code, there are two values for the scalars to be exported. One is at the inlet of the pipe and the second one at the outlet. To export a single value, the mean of the two values was exported to the thermal solver. The mean was calculated using custom scripts incorporated into the coupling tool.

\subsection{Turbocharger}

The MINI Clubman JCW has a twin scroll turbocharger. Only the effect of the turbine on the exhaust gas flow is considered for this modelling approach and the compressor is not explicitly modelled. This effect is simulated by modelling the turbocharger component using the turbine object in the 1D code.

As mentioned earlier, the performance maps of the turbocharger were used as a boundary condition for the 1D modelling. These were obtained by experiment. The turbocharger assembly was discretised to enable modelling the peripheral components around the turbine using 1D flow objects mentioned earlier. This was done to ensure the heat transfer scalars would be correctly transferred over to the thermal solver. Figure 9 shows the internal surface of the turbocharger geometry and how it was modelled in 1D.

There are two primary mechanisms for heat dissipation inside the turbocharger. One is via convection from the flow of the exhaust gas to the internal geometry and the other is via an enthalpy drop that occurs across the turbine. This drop happens because of the work performed by the exhaust gas on the turbine blades. The first mode of heat dissipation is modelled using 1D flow objects. The mechanism is the same as for any pipe object modelled in 1D.

To model the heat dissipated via the enthalpy drop, a heat rate was imposed on the turbine housing in the thermal solver. This was calculated in the 1D code and transferred over to the thermal solver using custom scripts. To calculate the heat rate, a calculation model was implemented inside the 1D code. This model is shown in the inset of Fig. 9. It is made up of three objects:

(a) RLT sensor: This receives the instantaneous values of the required results variables. RLT stands for resultvariable

(b) MathFormula: This calculates the result of a user specified formula

(c) RLTCreator: This creates and updates the heat rate variable

The formula used to calculate the heat rate $\dot{Q}$ is given by Eq. 4:

$\dot{Q}=-\dot{m} \eta \Delta h \chi$

where

$\dot{m}$ is the instantaneous mass flow rate in $\mathrm{kg} / \mathrm{s}$

$\eta$ is the corresponding isentropic efficiency of the turbine

$\Delta \mathrm{h}$ is the instantaneous specific enthalpy drop of the exhaust gas in the turbine in $\mathrm{J} / \mathrm{kg}$

$\chi(=0.1)$ is a user defined factor that governs the amount of heat that is transferred to the turbine housing

A value of $\chi=1$ would mean that the entire enthalpy drop across the turbine is transferred to the turbine housing. This is not actually the case, as only a part of the heat energy lost by the exhaust gas is transferred to the housing. The rest is dissipated to the cooling system and to the bearing housing by conduction via the turbine shaft. Hence, to ensure that the correct proportion of heat is transferred over to the turbine housing geometry, it becomes necessary to introduce the factor $\chi$. A value of 0.1 was found to have been used in similar studies [6] and also showed a good correlation with measurement data obtained from experiments.
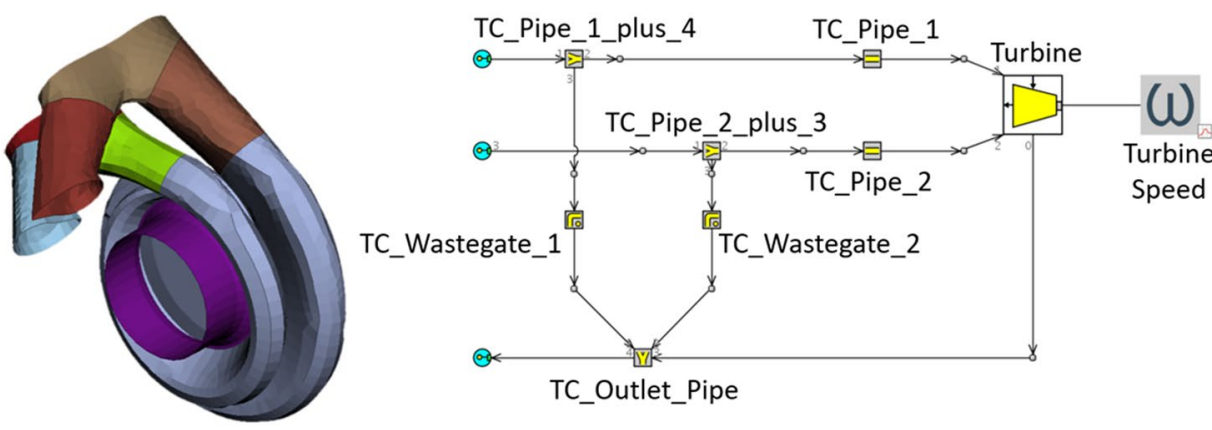

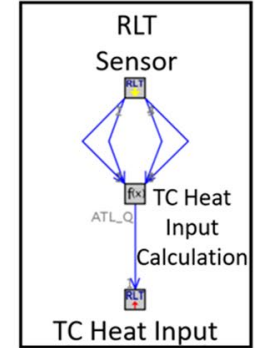

$\mathrm{TC} \rightarrow$ Turbocharger

Fig. 9 Modelling of the turbocharger in the 1D code 


\subsection{Catalytic converters and middle acoustic silencer}

The modelling approach of the PCC, SCC and MAS is explained together as the three components have similar heat transfer mechanisms inside of them. For this reason, the technique developed to model them is similar as well.

Figure 10 illustrates the cross section views of these components.

The geometry of the substrate inside the catalytic converter is modelled by specifying its diameter, length and cell density per unit area. The pipe components of the MAS are modelled using the same technique that was utilized for the rest of the pipes.

In catalytic converters, the surface temperature is primarily determined by the convection heat transfer to the substrate walls and the subsequent conduction through the fiber mat and the outer metal housing [13, 24, 32, 35, 36]. For an acoustic silencer packed with a porous absorption material, the mechanism is similar in that the heat is transferred via convection first to the pipe walls and then via conduction through the porous material and outer metal housing. For both the components, the convection heat transfer is calculated by the $1 \mathrm{D}$ code. To model the conduction through the various layers effectively, a modelling approach known as Thermal Mass Modelling (TMM) was developed. In this, each layer is modelled as a thermal mass in the $1 \mathrm{D}$ code. The thermal mass object used inside the 1D code represents a 3D component using only its thermal mass. This is defined as in Eq. 5. The TMM approach is shown in Fig. 11.

$C_{\mathrm{th}}=m \cdot c_{p}$

where
Fig. 10 Internal construction of SCC and MAS

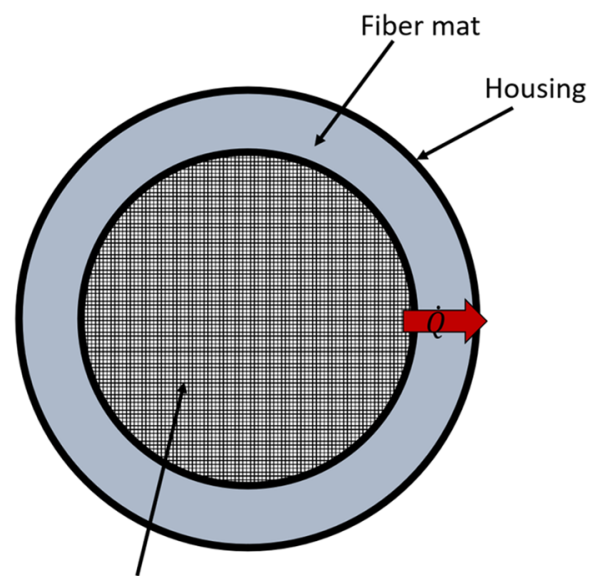

Substrate

Primary / Secondary Catalytic Converter

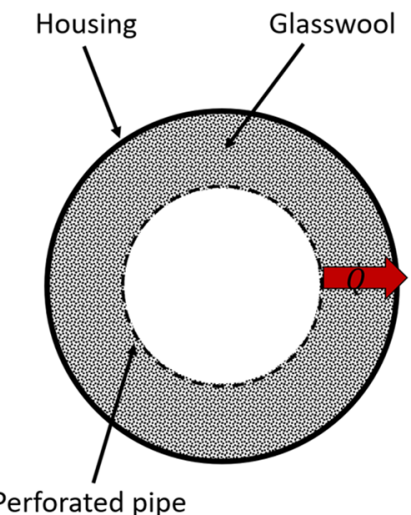

Middle Acoustic Silencer
Fig. 11 Modelling of the SCC and MAS in 1D code
Conduction connection
Convection connection

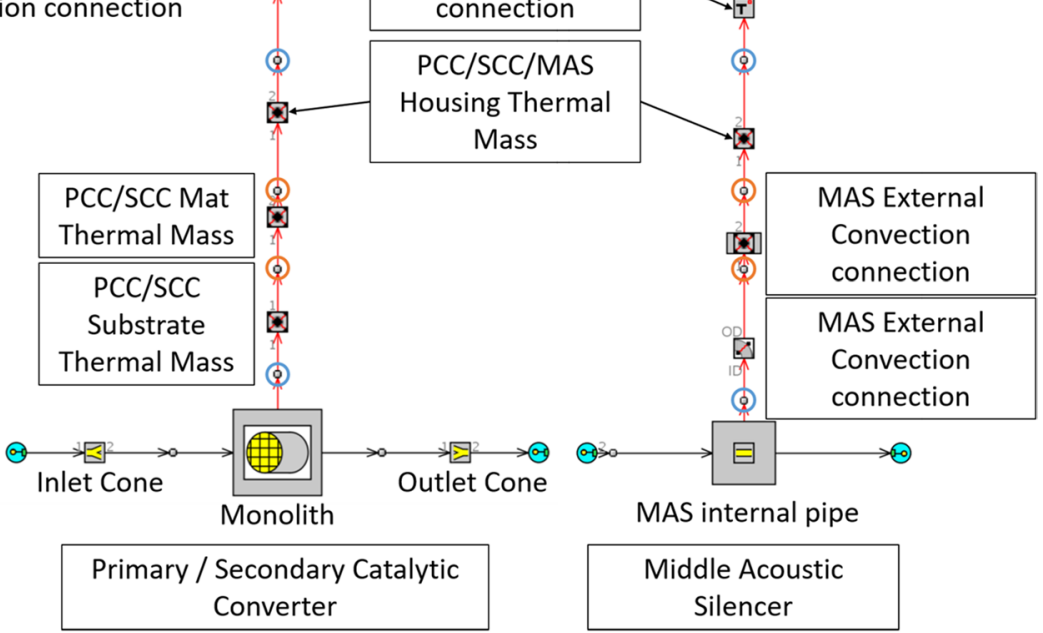


$C_{\text {th }}$ is the thermal mass of the object in $\mathrm{J} / \mathrm{K}$

$\mathrm{m}$ is the mass of the object in $\mathrm{kg}$

$c_{p}$ is the specific heat capacity of the material in $\mathrm{J} / \mathrm{kg} \cdot \mathrm{K}$

To model the heat transfer for the thermal masses, connection objects inside the 1D code were used. These objects simulate the convection or conduction heat transfer occurring at the ports of boundaries of the thermal mass. These connection objects and their respective thermal mass connections are shown in Fig. 11. As mentioned earlier, the heat transfer from the internal to the external surface is modelled by exporting a heat rate to the thermal solver which sends a surface temperature back to the $1 \mathrm{D}$ code as a boundary condition at the external surface. There is also the heat lost via convection at the external surface which is modelled via an external convection object. This connection receives the convection data from the 3D CFD solution.

The definition of a thermal mass in the 1D code needs the specification of its heat transfer ports. These are the interfaces through which heat enters and exits the thermal mass. In the case of the SCC, PCC and MAS the ports are the cylindrical contact surfaces between the layers. Each port is defined by its distance to the centre of mass of the object and its surface area. An example of this is shown in Fig. 12. Thermal mass for layer- 2 is defined with Port-2 and Port-3. The areas used are A2 $(\pi \cdot \mathrm{D} 2 \cdot \mathrm{L})$ and A3 $(\pi \cdot \mathrm{D} 3 \cdot \mathrm{L})$, respectively. The distance from the centre of mass for both the ports is $\mathrm{t} 2 / 2$.

\subsection{End acoustic silencer}

The End Acoustic Silencer (EAS) for the exhaust system on the MINI Clubman JCW is a multi-chambered design. It has a single inlet, two outlets and internal piping. The details of the internal structure are shown in Fig. 13. It is divided into 5 chambers which are separated by perforated baffles. Chambers 3 and 4 are filled with porous material,

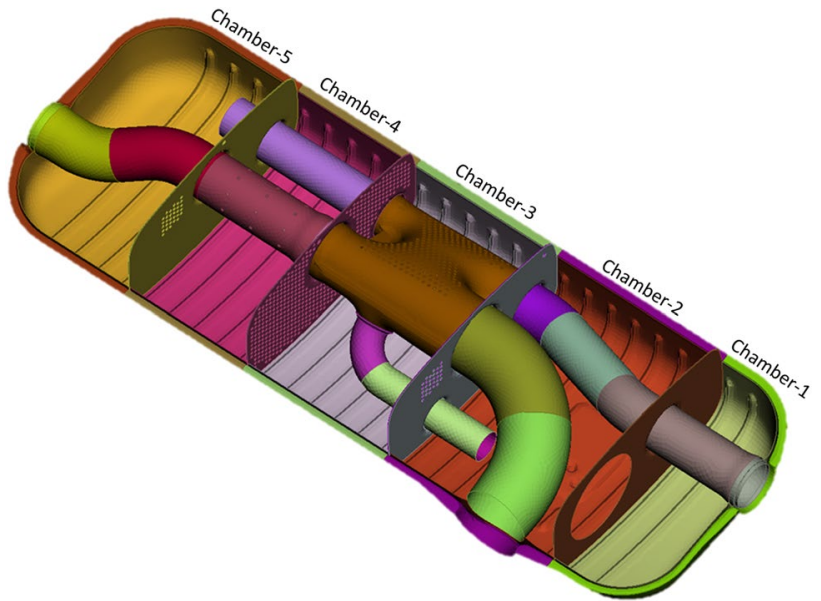

Fig. 13 End Acoustic Silencer internal structure splitting

i.e., glasswool. The rest of the chambers are open to the flow of exhaust gases.

Heat transfer inside a multi-chamber acoustic silencer consists of 5 phenomena, listed in Table 3.

The first of the convection heat transfer processes is accounted for by modelling the internal piping of the EAS with the same method used for the rest of the pipes in the exhaust system. To model the second convection heat transfer process, the open chambers were included in the flow circuit of the EAS and modelled using conventional flow objects in $1 \mathrm{D}$.

To model the third heat transfer process, the TMM approach introduced earlier was used. However, the approach had to be modified as the chambers containing glasswool are not axisymmetric unlike the other components that this approach was used for. There are also multiple pipes inside a single chamber that are in contact with the glasswool. To model the glasswool using the TMM approach, the space occupied by it inside the chamber was discretized
Fig. 12 Thermal mass modelling in $1 \mathrm{D}$ code

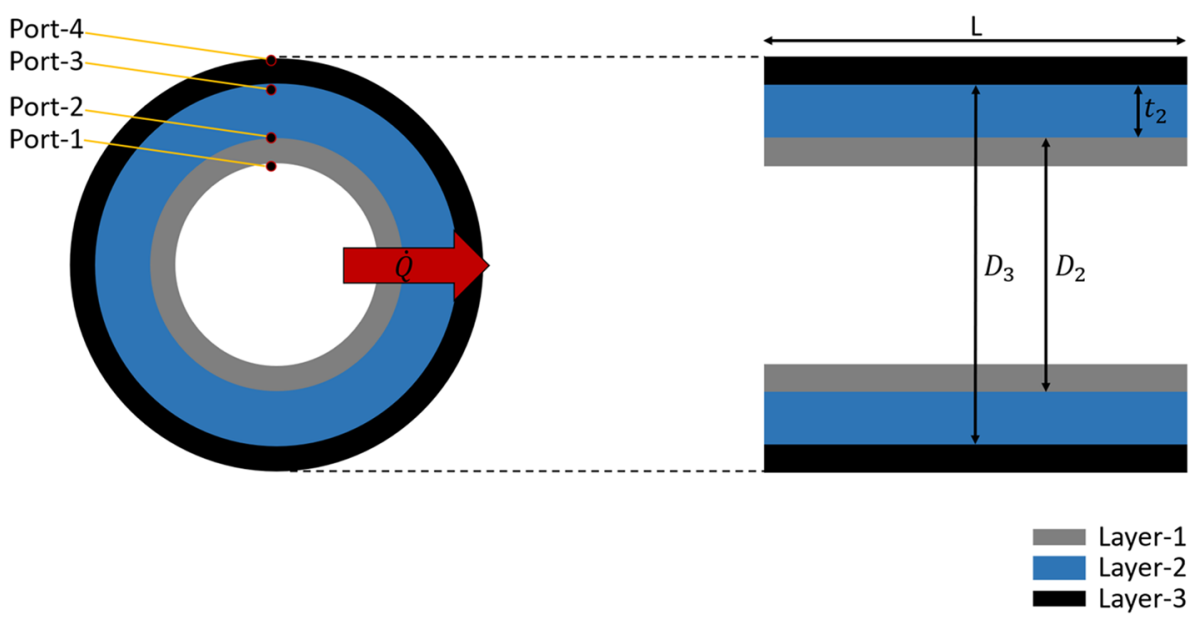


Table 3 Heat transfer phenomena in the EAS

\begin{tabular}{ll}
\hline 1 & Convection of heat from exhaust gas to the pipe walls \\
2 & Convection of heat from exhaust gas to the chamber walls (open chambers) \\
3 & Conduction of heat from pipe external surface to chambers through porous \\
material (packed chambers) \\
Conduction of heat between pipes, baffles and chambers \\
5 & Radiation of heat from pipe external surface to chamber surface \\
\hline
\end{tabular}

Fig. 14 Discretisation of glasswool heat transfer ports for a pipe in Chamber-4

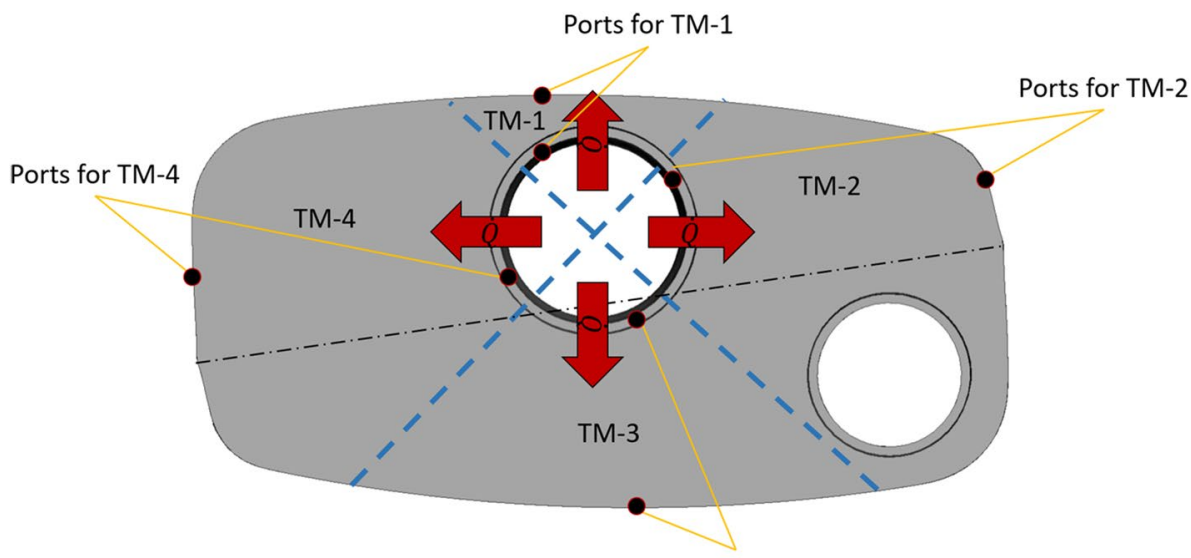

Ports for TM-3 and modelled as an individual thermal mass for each pipe in contact with it. The glasswool was discretized into four thermal masses for each pipe to capture the conduction heat transfer between the pipe and glasswool in the four principal directions. Figure 14 shows the discretization of the glasswool for one of the pipes from Chamber-4.

It can be seen that the space occupied by the glasswool has been split into four thermal mass objects (TM-1 to TM-4). Each thermal mass has two ports. One is connected to the port and the second is connected to the housing. The seam between the upper and lower housing parts of the Chamber- 4 is represented by the dashed black line in Fig. 14. As the pipe shown is almost entirely in the upper half of the chamber, the conduction heat transfer from TM-2 and TM-4 is assumed to be entirely to the upper half of the housing. This assumption was made to reduce the modelling complexity and improve applicability of the approach to other EAS models. It has been applied wherever appropriate. The rest of interfaces between glasswool and pipes in Chambers 3 and 4 were modelled using the same approach. The resulting conduction heat transfer rates to the chamber housing were exported to the thermal solver.

The conduction from the pipes to the external chamber and radiation from the pipe surfaces to the open chambers are accounted for in the thermal solver. The accuracy of the calculation of these heat transfer processes depends on the accuracy of the modelling of the first three modes in 1D. With the modelling of all the five processes complete, the heat transfer profile of the EAS is complete and it can be integrated into the rest of the 1D model to complete the modelling of the exhaust system.

\subsection{D/3D hybrid}

The previous two sections describe the completely 3D and completely 1D modelling of the exhaust system. Each of the approaches has its merits and limitations. With the objective of combining the advantages of both the approaches, a new hybrid methodology was developed. There have been a few studies in the past that explored this option [29, 30]. However, those works have mainly focused on modelling parts of the exhaust system as a 1D/3D hybrid. The methodology proposed in this paper is aimed at developing a simulation model for the hybrid approach that can be utilized for a complete exhaust system. This would then be integrated into a full VTM simulation workflow.

The methodology was developed in two phases:

1. The partially modular approach, wherein the piping structure of the exhaust was modelled both in 1D and 3D. The components such as the turbocharger, PCC, SCC, MAS and EAS were modelled only in 1D

2. The fully modular approach, where the piping structure was modelled only in 3D and the other components were modelled only in $1 \mathrm{D}$ 


\subsection{Partially modular}

For this phase, the 1D modelling as described in the previous section was used as the starting point on the 1D side of the hybrid model. The only modification on the initial 1D model was that the HTC and fluid temperature values were no longer exported to the thermal solver. Mass flow rate, fluid temperature and total pressure values were instead exported to the 3D CFD solver to be used as boundary conditions at the interface between the pipes and the 1D components mentioned earlier.

At the 3D end of the hybrid approach, only the pipes were modelled as individual 3D regions. This is shown in Fig. 15. Each region has an inlet and outlet boundary defined, the boundary conditions of which are set via the values imported from the $1 \mathrm{D}$ solver. The entire process was automated and controlled via a coupling software and all the boundary conditions were updated at every coupling loop.

As already mentioned, the entire exhaust system was modelled in 1D for this phase of the development. In addition, the heat transfer variables were also calculated inside the 3D pipes. These variables were then exported to the thermal solver which calculates the surface temperatures and sends them back to the 3D and 1D codes. This redundancy in calculation of the heat transfer variables is one of potential areas of optimization for this process. This approach is called the partially modular approach, as there is no feedback loop between the 3D pipes and the $1 \mathrm{D}$ components. This is because the $1 \mathrm{D}$ model is complete on its own and the 1D pipes provide the feedback to the other components. For complete modularity, the $1 \mathrm{D}$ model would consist only of those specific components. They could then be interchanged to simulate different exhaust configurations. The model developed in this phase served as a base to develop the fully modular approach, which is explained in the next sub-section.

\subsection{Fully modular}

For the fully modular phase of the hybrid methodology development, the 3D modelling was the same as for the partially modular approach. The 1D modelling was changed to include all the components other than the pipes. This is shown in Fig. 16.

As can be seen in Fig. 16, all the components have been modelled individually. Each of them has its own inlet and outlet object defined with it. These objects are the connections to the pipes in the 3D code and they complete the flow network. Same as with the partially modular approach, mass flow rate, total pressure and fluid temperature were exported to the 3D CFD code. As a feedback from the 3D code, total pressure and fluid temperature values at points just downstream from the inlets and just upstream from the outlet were sent back to the 1D model. These were set as boundary conditions in the 1D model. The whole process was automated and run in an iterative fashion. The flow and exchange of variables is explained in Fig. 17.

It can be seen that the variables are being exchanged at the interfaces of the models to allow for a continuity in flow that would iteratively achieve steady state conditions across the two models. The HTC values are exported to the thermal
Fig. 15 Pipes modelled in 3D for the partially modular hybrid approach

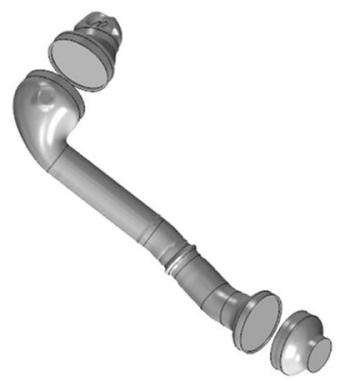




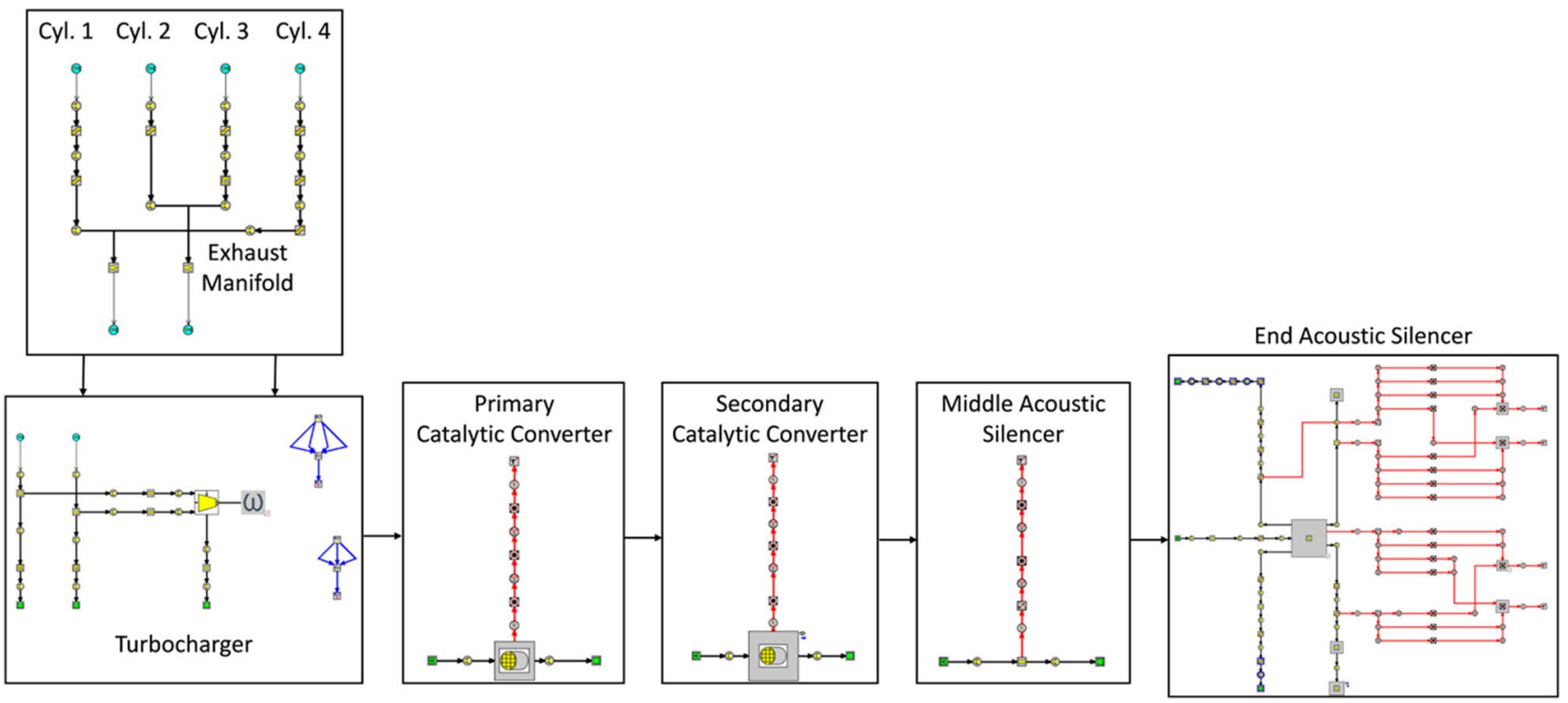

Fig. 16 1D Model for the fully modular approach

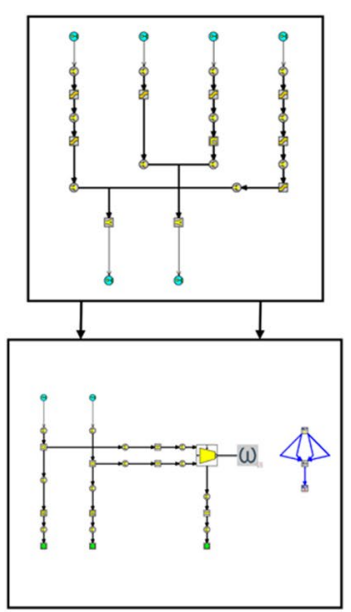

Turbocharger in 1D

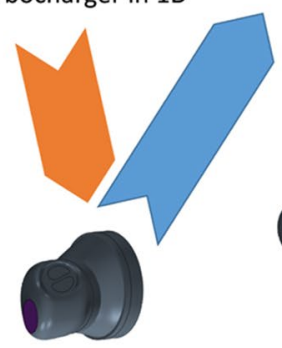

Pipes after turbocharger and before PCC
Flow of Total Pressure and Temperature values being exchanged between 1D and 3D Models

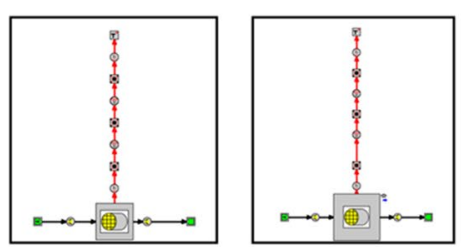

$\mathrm{PCC}$ in 1D

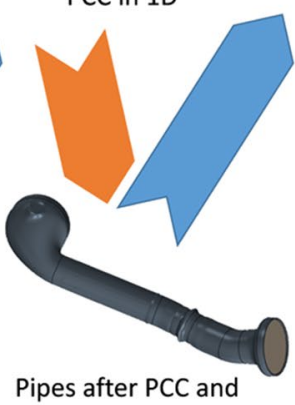

before SCC

SCC in 1D

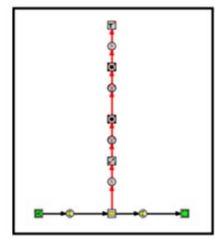

MAS in 1D
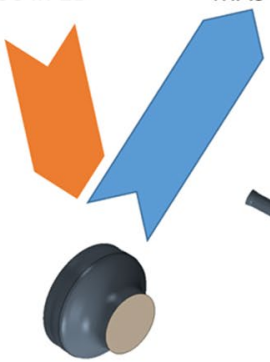

Pipes after SCC and before MAS

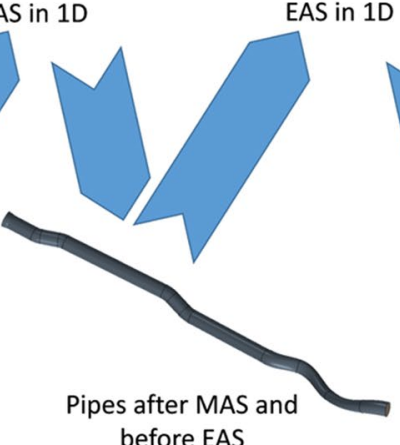

before EAS
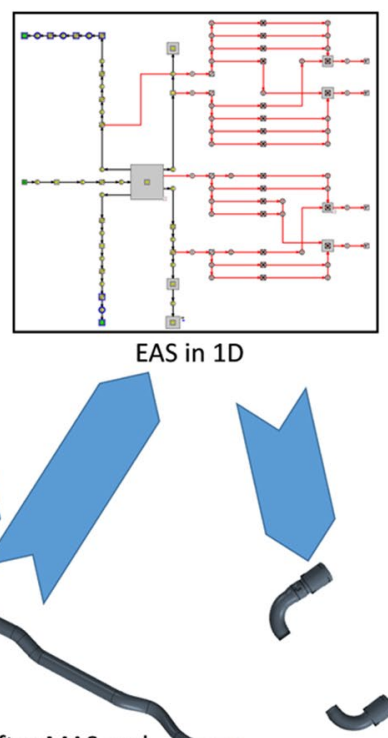

Tailpipes

Fig. 17 Exchange of variables between 1D and 3D model for the fully modular approach

solver in the same manner as with the partially modular approach.
As mentioned briefly in the 3D modelling section, a novel custom approach was developed to export the HTC values from within the pipes. This technique was utilized for both 
the partially and fully modular variants. The aim behind developing this method was to overcome the variability in exported scalar values caused by local inconsistencies in mesh quality. This was done by exporting the value from a constant wall distance using an iso-surface. The value of fluid temperature is probed at this iso-surface and a custom value for the HTC is calculated based on this fluid temperature. This is shown in Eq. 6. The constant distance for the iso-surface cannot be too close to the wall as it will be influenced by the interaction of the exhaust gas with the wall. It can also not be too far away from the wall so as to avoid interpolation errors and unrealistically high temperature values. The distance chosen for this purpose was between the freestream of the exhaust gases and the wall. The iso-surface of the wall distance is shown in Fig. 18:

$h_{\text {custom }}=\frac{\vec{\Phi}_{\mathrm{q}}}{\left(T_{\text {iso }}-T_{s}\right)}$

where

$h_{\text {custom }}$ is the custom heat transfer coefficient in $\mathrm{W} / \mathrm{m}^{2} \cdot \mathrm{K}$ $\vec{\Phi}_{\mathrm{q}}$ is the heat flux in $\mathrm{W} / \mathrm{m}^{2}$

$T_{\text {iso }}$ is the Tfluid value at the isosurface in $\mathrm{K}$

$T_{s}$ is the surface temperature value at the pipe surface in $\mathrm{K}$

\section{Results}

Figures 19 to 23 in this section all show absolute values of the delta between experiment and simulation. The delta has been calculated by subtracting the experimental value from the simulated value. Hence, a positive value represents higher temperatures in simulation and vice versa.
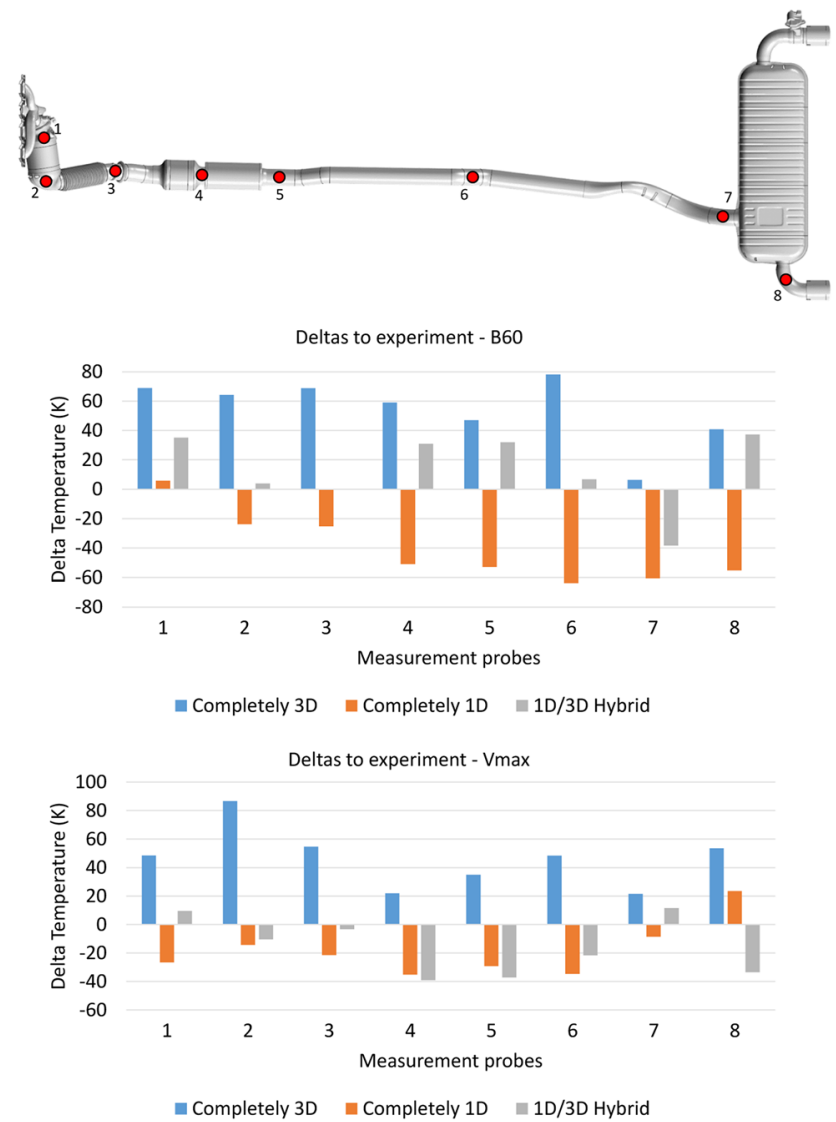

Fig. 19 Comparison of exhaust gas temperatures between experiment and simulation for B60 and Vmax loadcases

\subsection{Exhaust gas temperatures}

Figure 19 shows the comparison between the experimental values of the exhaust gas temperatures and those predicted by the three approaches developed for this study, at different locations across the exhaust system.
Fig. 18 Iso-surface of the wall distance used for HTC and TFluid calculations

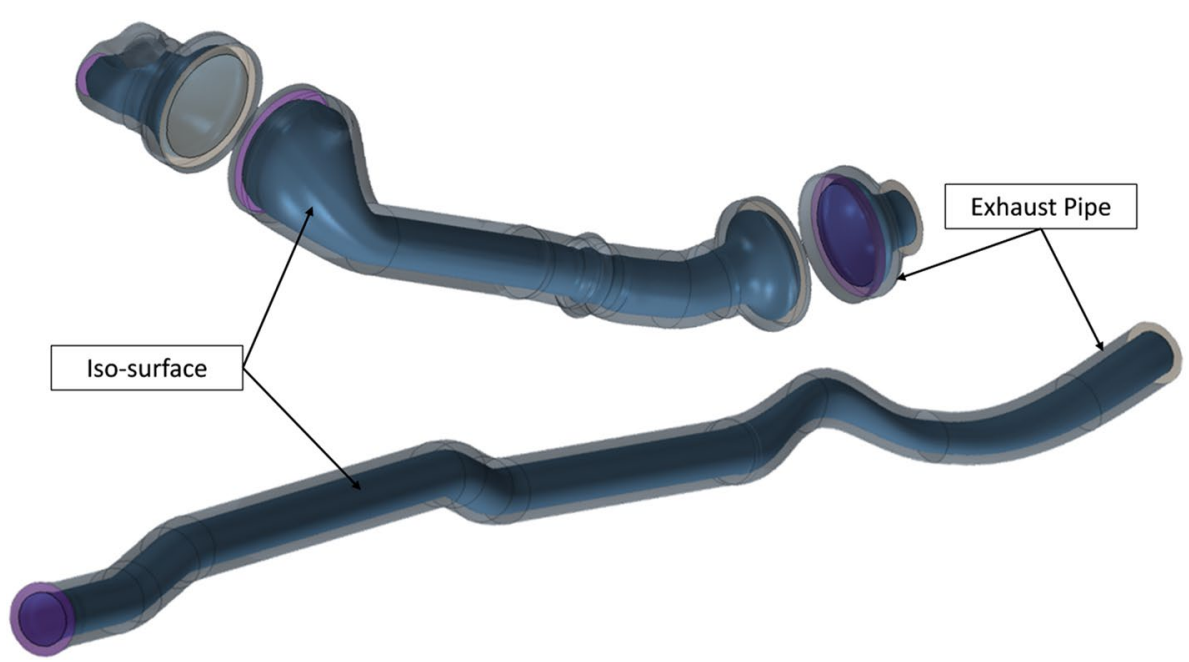


From Fig. 19, it can be seen that the temperatures returned by the completely $3 \mathrm{D}$ approach have the highest discrepancy. The completely 1D approach is better matched but the hybrid approach has the best agreement to the experimental values across all the measurement probes on an average.

The temperature values returned by the completely $3 \mathrm{D}$ approach are also higher than in experiment, while those of the completely 1D approach are lower than in experiment. The reason for the behavior in the 3D method is the same issue of the local mesh inconsistencies mentioned earlier. For the completely 1D methodology, the issue arises due to the fact that a single heat transfer coefficient is applied over the entire length of the pipe.
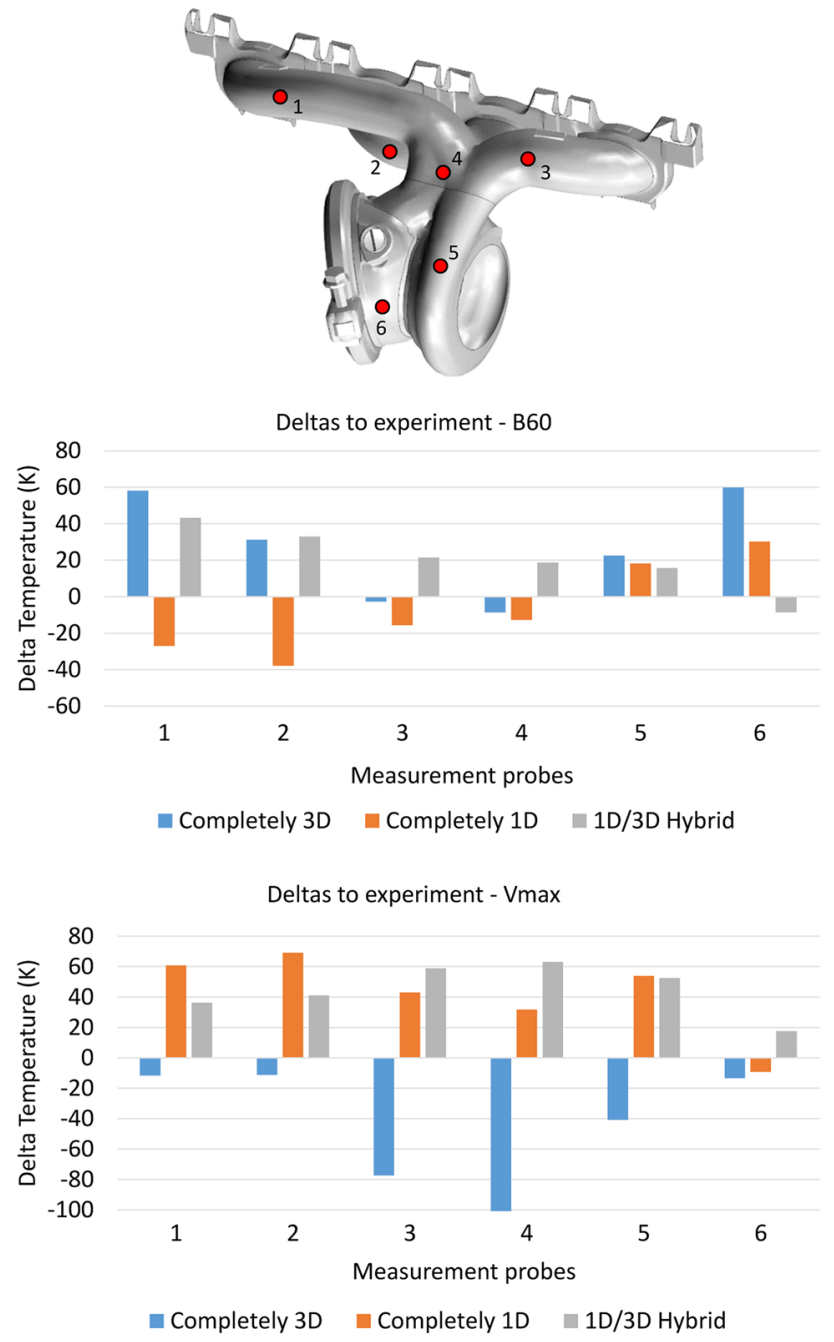

Fig. 20 Comparison of manifold and turbocharger surface temperatures between experiment and simulation for B60 and Vmax loadcases

\subsection{Hot end results}

\subsubsection{Manifold and turbocharger}

A comparison of measured and simulated surface temperatures for the exhaust manifold and turbocharger is shown in Fig. 20. Probe 1 is located on the primary pipe coming out of cylinder one, the second probe is on the pipe coming out of cylinder two, probe 3 is at the end of the cylinder four pipe just above the waste gate. Probe 4 is placed on the confluence of the primary pipes coming out of cylinders one and four. Probes 5 and 6 are on the turbocharger assembly.

For the completely 3D approach, the probes are well matched to the experiment in general. The differences come from a few of the modelling choices adopted for this approach. The main one being the steady state approximation of the inlet boundary conditions. This reduces the heat transfer effect of the transient mixing of the exhaust gases. The effect is primarily seen in probes 3 and 4 . At probe 5, the discrepancy comes from the method used to simulate the enthalpy loss over the turbine. It underpredicts the heat energy lost to the turbine housing, even though the results are within acceptable tolerances. For probe 6, the difference is bigger in $\mathrm{B} 60$ than in Vmax. This is because the wastegate modelling in both the loadcases was the same, which led to exhaust flowing through it in the B60 case when there should have been no flow.

In the completely $1 \mathrm{D}$ approach, the deltas are lower than in the completely 3D method. This is because the transient effects are better captured in the 1D simulation than in the $3 \mathrm{D}$ simulation. The $1 \mathrm{D} / 3 \mathrm{D}$ hybrid approach shows values that lie in between those of the completely $1 \mathrm{D}$ and $3 \mathrm{D}$ approaches on an average across all the measurement probes. The components with probes 1 to 5 are modelled in 1D and only the one with probe 6 is modelled in 3D. The slight discrepancy between the components modelled in 1D between the two methods comes from the interaction between this 3D component and the 1D components surrounding it.

Although the difference in surface temperatures between the simulated and measured values seems high, the delta between the two values is quite insignificant when compared to the absolute values of the temperatures on these surfaces. These values exceed $1000 \mathrm{~K}$ in the region, where these probes are placed.

\subsubsection{Primary catalytic converter}

Figure 21 shows a comparison of the measured and simulated surface temperatures at the measurement locations shown on the surface of the Primary Catalytic Converter (PCC). Probes 1 and 2 are on the inlet to the catalytic converter. Probes 3 and 4 are on the catalytic converter above, 

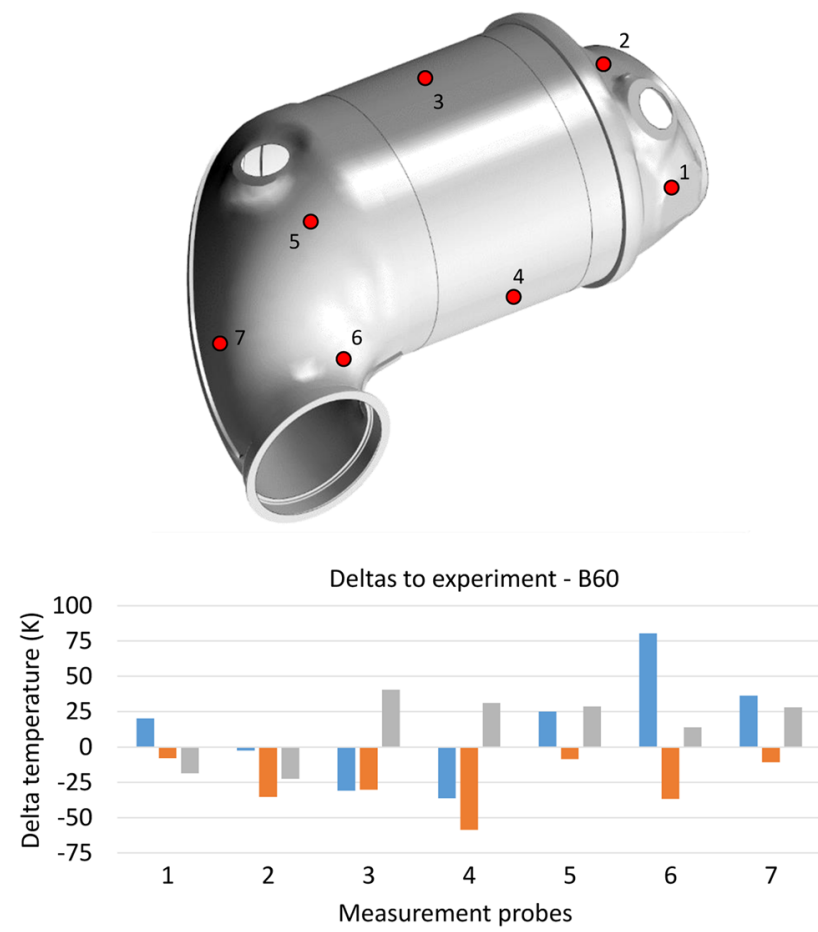

Completely 3D Completely 1D $\square$ 1D/3D Hybrid

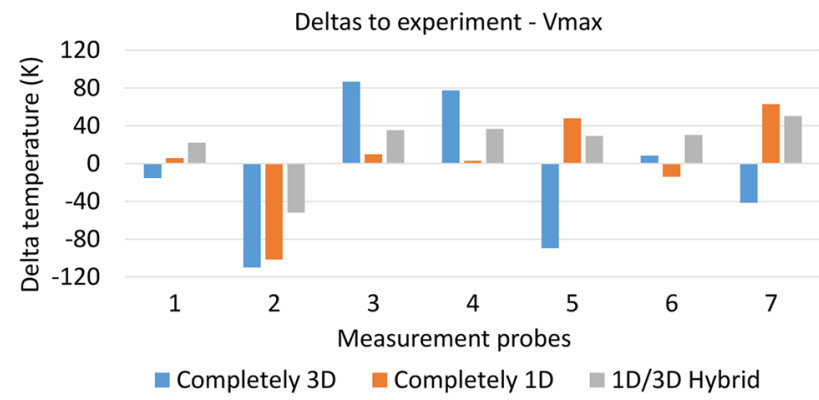

Fig. 21 Comparison of Primary Catalytic Converter surface temperatures between experiment and simulation for B60 and Vmax loadcases

where the monolith is located. Probes 5 to 7 are on the outlet from the PCC.

For the completely $3 \mathrm{D}$ approach, the first probe shows good agreement with the experiment. The discrepancies for the rest of the probes arises from a combination of the deficiency in the calculation of the HTC values as already mentioned and the method employed to model the exothermic reaction inside the monolith. The latter is primarily evident in probes 3 and 4 . In case of the PCC, values for the completely 1D approach are better matched to the experiment than those of the completely 3D approach. The primary cause of discrepancies is the limited spatial fidelity of this method. This is seen mainly
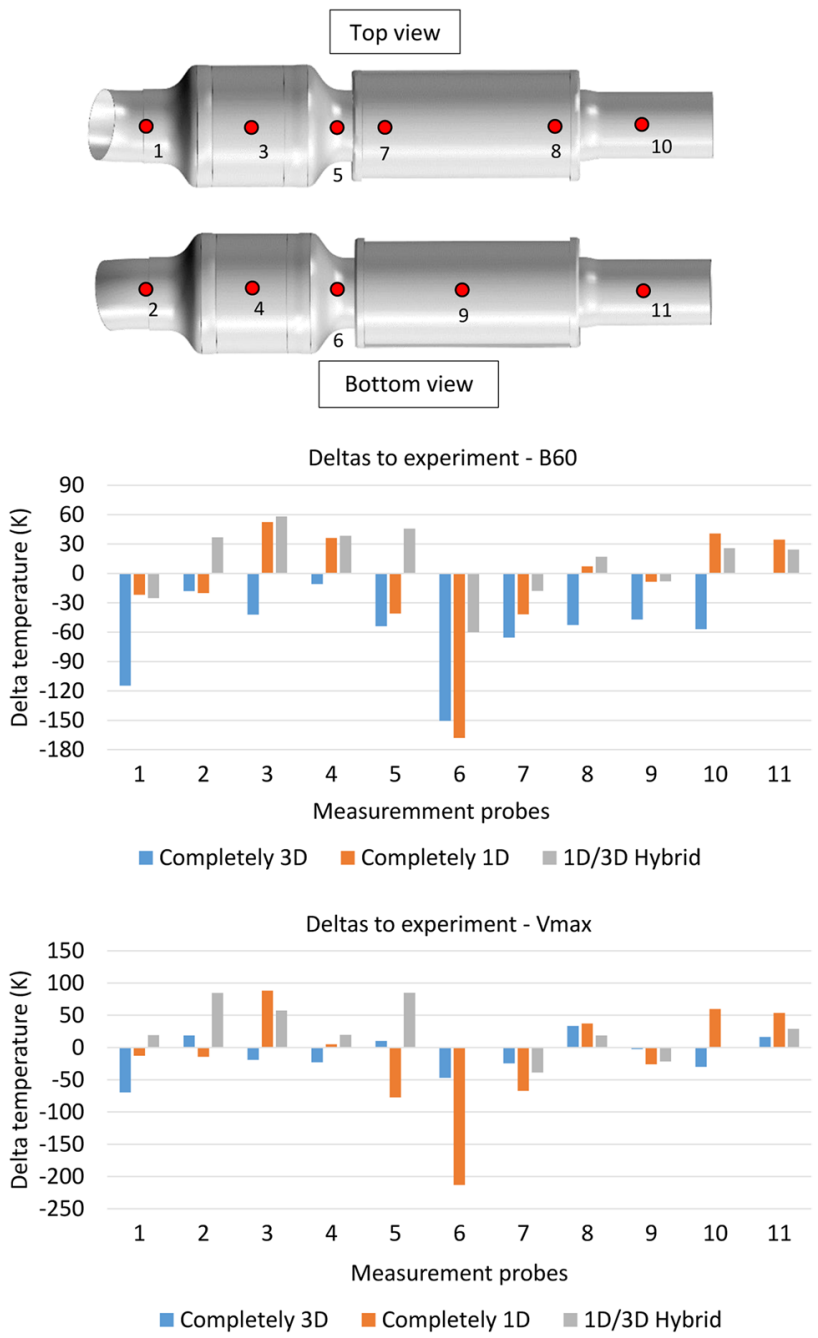

Fig. 22 Comparison of SCC and MAS surface temperatures between experiment and simulation for B60 and Vmax loadcases

in probes 2 and 6 . The heat released by the monolith to the surface is also lower due to the lower temperatures of the exhaust gases.

Using the hybrid approach, the temperature values returned show a closer match to the experimental results than the other two methods. This is partly because of the modelling of the inlet and outlet cones in 3D and partly because of the method employed to calculate the heat transfer variables in the hybrid method.

As was the case with the exhaust manifold and turbocharger area, the discrepancies in temperatures for the PCC are insignificant as well. The temperature values in this region are also above $1000 \mathrm{~K}$.

\subsection{Cold end results}

The following subsection discusses the results for the cold-end of the exhaust system. The cold-end comprises 
of everything after the flex-coupling element up to the end acoustic silencer.

\subsubsection{Secondary catalytic converter and middle acoustic silencer}

Figure 22 shows a comparison of the measured and simulated surface temperatures at the probe positions shown on the surface of the Secondary Catalytic Converter (SCC), Middle Acoustic Silencer (MAS) and the surrounding pipes. Probes 3 and 4 are on the surface of the SCC, while 7, 8 and 9 are on the MAS. The rest of the probes are on the piping system.

The completely $3 \mathrm{D}$ approach shows a better agreement with the experimental values for the Vmax loadcase than for B60. The temperatures for both the cases are lower than in experiment on an average, but the deltas for B60 are higher. The differences mostly arise from the aforementioned calculation method for the heat transfer variables used in the completely 3D approach. Probes 1 and 6 in particular are most affected by this. Probe 1 lies on the opposite side of an impingement point on the exhaust and probe 6 lies at the lower end in an area of the pipe, where turbulent effects are predominant. The same probes have smaller deltas in the Vmax loadcase due to higher flow temperatures and velocities involved. There is a better correlation with the experimental values for the $1 \mathrm{D}$ results in comparison to the completely $3 \mathrm{D}$ results on an average. However, the probes placed on the pipes show a higher delta for the 1D simulation than for the 3D simulation. This is because of the limited spatial accuracy of the 1D simulation. This drawback is especially highlighted by probe 6 . The $1 \mathrm{D}$ approach struggles to model the complex three dimensional turbulent flow in that section of the pipe.

The hybrid modelling approach shows a noticeable improvement over the other two modelling techniques. The results with this method show an acceptable correlation with the experimental values, the most significant one being at probe 6 which is notably closer to experiment than in both the other modelling methods.

\subsubsection{End acoustic silencer}

Figure 23 shows a comparison of the measured and simulated surface temperatures at the probe positions shown on the surface of the End Acoustic Silencer (EAS). A total of 14 measurement probes were mounted onto the EAS to be able to capture its temperature profile as closely as possible. Probes 1 and 2 are located on the inlet pipe to the EAS. Probe 14 is on the left tail-pipe of the vehicle. The rest of the probes are placed on the different chambers of the EAS.
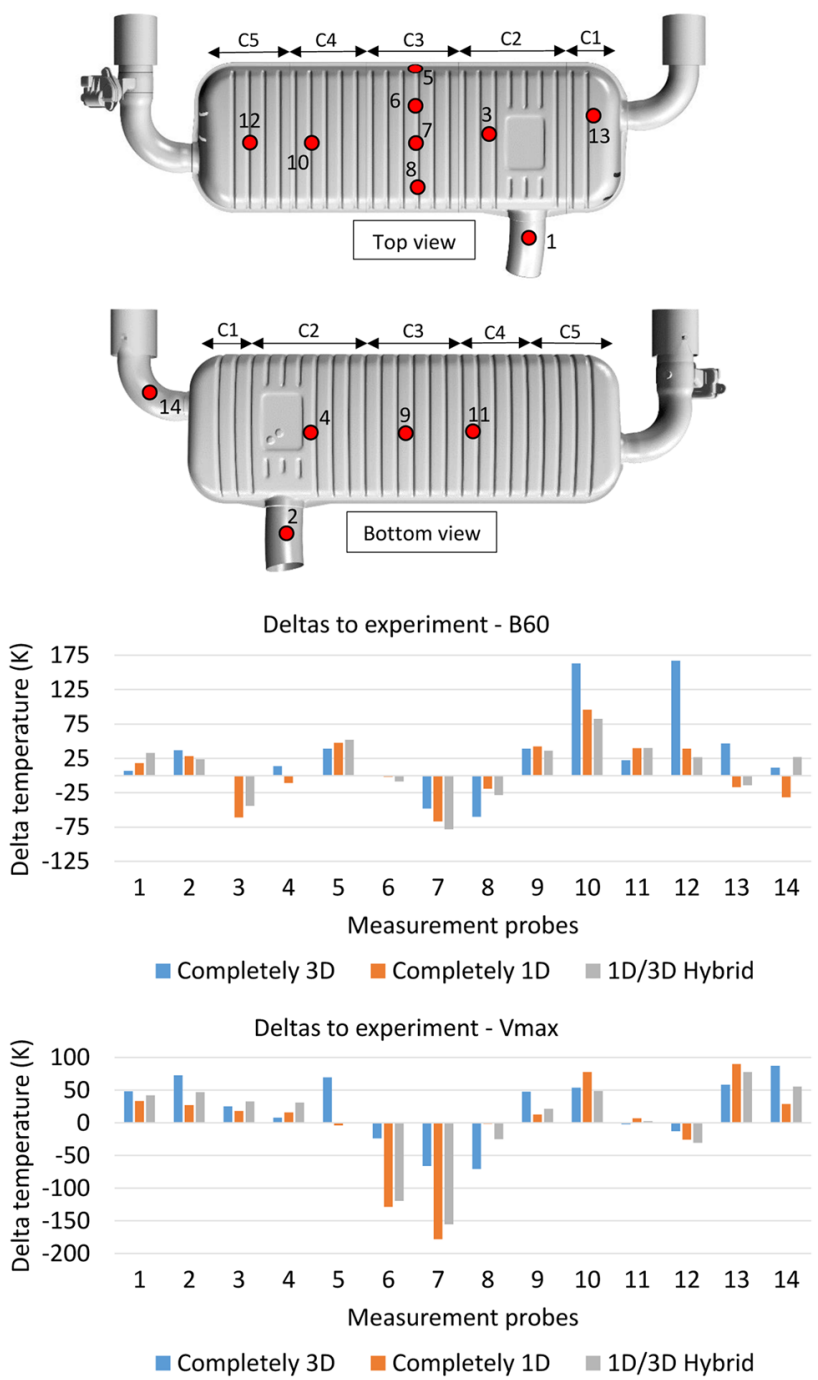

Fig. 23 Comparison of EAS surface temperatures between experiment and simulation for B60 and Vmax loadcases

Chambers $\mathrm{C} 3$ and $\mathrm{C} 4$ are the ones filled with the porous dampening material.

The results returned for the EAS show a fairly good agreement with the experimental values for all the three methods of development. The biggest deltas arise due to the difficulty and limitation in accurately modelling the thermal behaviour of the porous glasswool inside the chambers $\mathrm{C} 3$ and $\mathrm{C} 4$. For the $3 \mathrm{D}$ approach, this is seen most prominently at probes 10 and 12. For the other two methods, it is seen at probes 6 and 7. The highest delta occuring in the Vmax loadcase for the 1D approach. The 1D and hybrid approaches have the same temperature profiles, because both approaches use the same modelling for the EAS. The slight differences in temperature arise from the fact that the inlet pipe to the EAS is modelled as 3D in the hybrid approach. This causes the inlet gas temperatures to the EAS to be higher than in the completely 1D approach. Despite this difference, the 

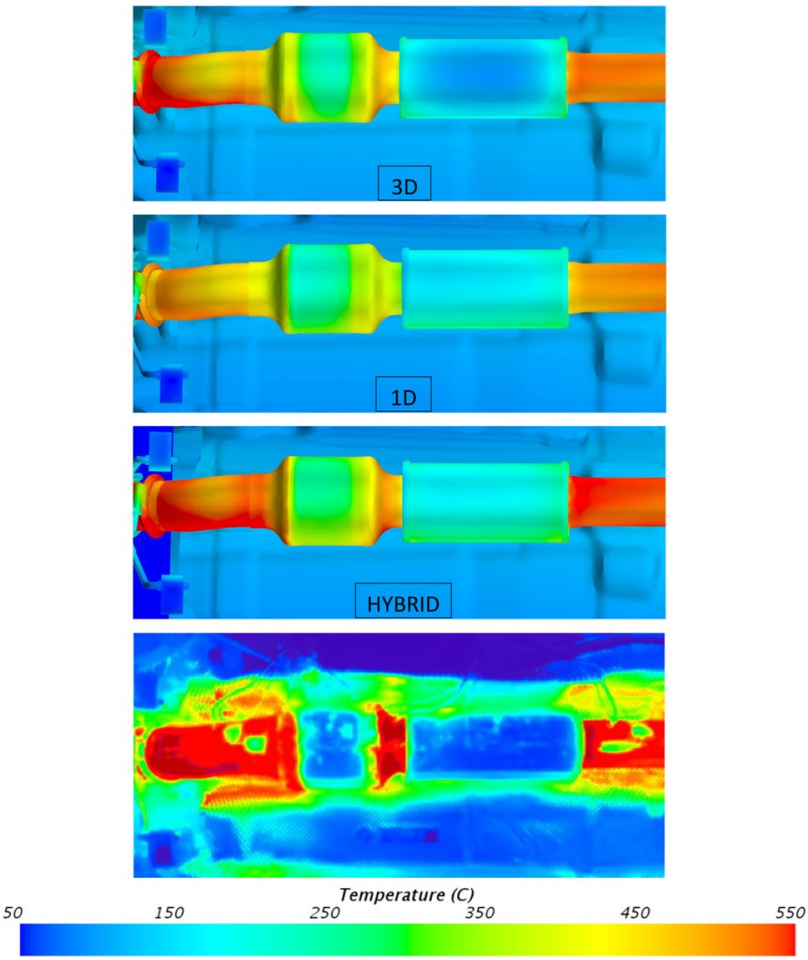

Fig. 24 Comparison of the B60 thermography image with the 3D, 1D and Hybrid simulated surface temperature distribution on the SCC and MAS

temperature profile of the two methods for EAS modelling is identical. This becomes clearer in the next section.

\section{Qualitative validation with thermography}

The temperature distribution on the surface of the exhaust system was qualitatively validated using thermography.

\subsection{Cold-end: secondary catalytic converter and middle acoustic silencer}

Figures 24 and 25 show the temperature gradients on the bottom side of the SCC, MAS and surrounding pipes for all the three simulation methods together with the thermography images. The completely 3D and the hybrid approach capture the gradients relatively better than the 1D method. However, all three of the developed methodologies show a fairly good agreement with the thermography images.

\subsection{Cold-end: end acoustic silencer}

A qualitative comparison for the EAS between simulation and experiment is shown in Figs. 26 and 27. It can be seen that the temperature profiles for the EAS is similar between
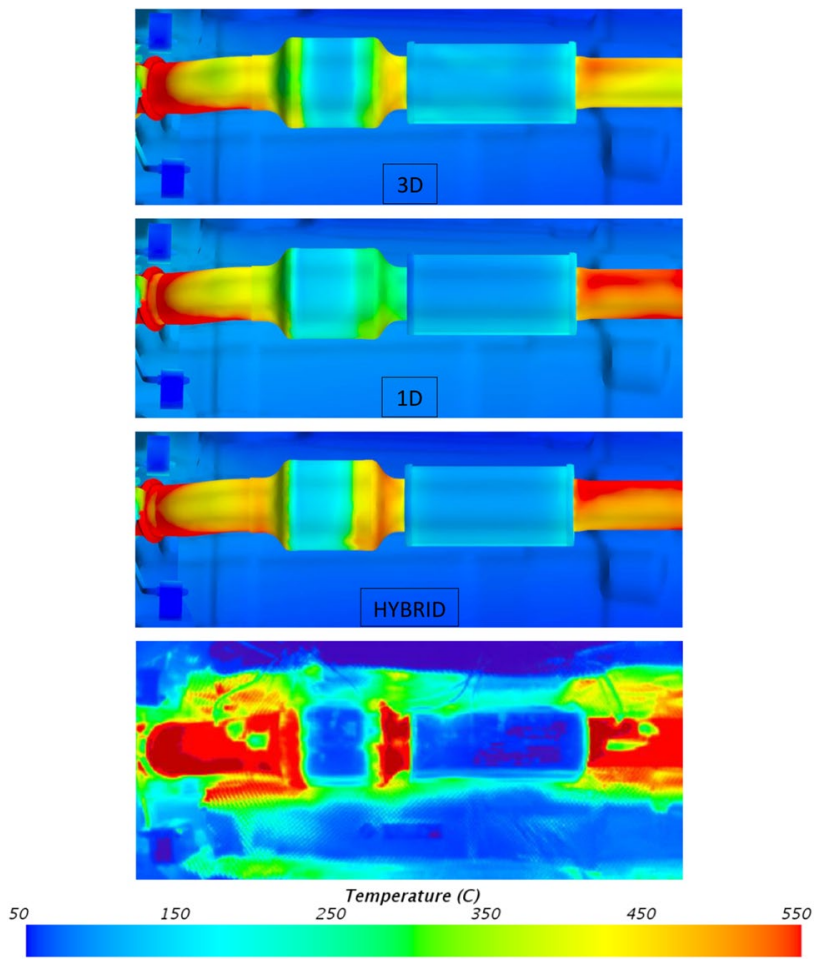

Fig. 25 Comparison of the Vmax thermography image with the 3D, 1D and Hybrid simulated surface temperature distribution on the SCC and MAS

the 1D and hybrid approaches. The completely 3D approach captures some hotspots better than the other two methods, but overall the temperature gradients between simulation and experiment match to an acceptable level.

\subsection{Summary of results for the exhaust system module}

The different methodologies developed for the simulation of the exhaust system in a vehicle have been extensively compared. A total of 46 measurement probes on the exhaust system and a qualitative comparison of the temperature gradients was performed to assess them. This study was a part of a larger research aiming to develop a modular methodology for VTM simulations. Therefore, only one of the three developed methods needed to be selected to be integrated into a coupled VTM simulation workflow.

The choice for which of the three methods can be chosen for the full vehicle simulation workflow depends on a number of different criteria. A decision table was utilized for this purpose and is shown in Table 4. The criteria chosen were the complexity of the modelling process, the accuracy of the simulation method, the scope for modularity, the applicability across different types of complete vehicle simulations, and the turnaround time of the entire simulation process. 

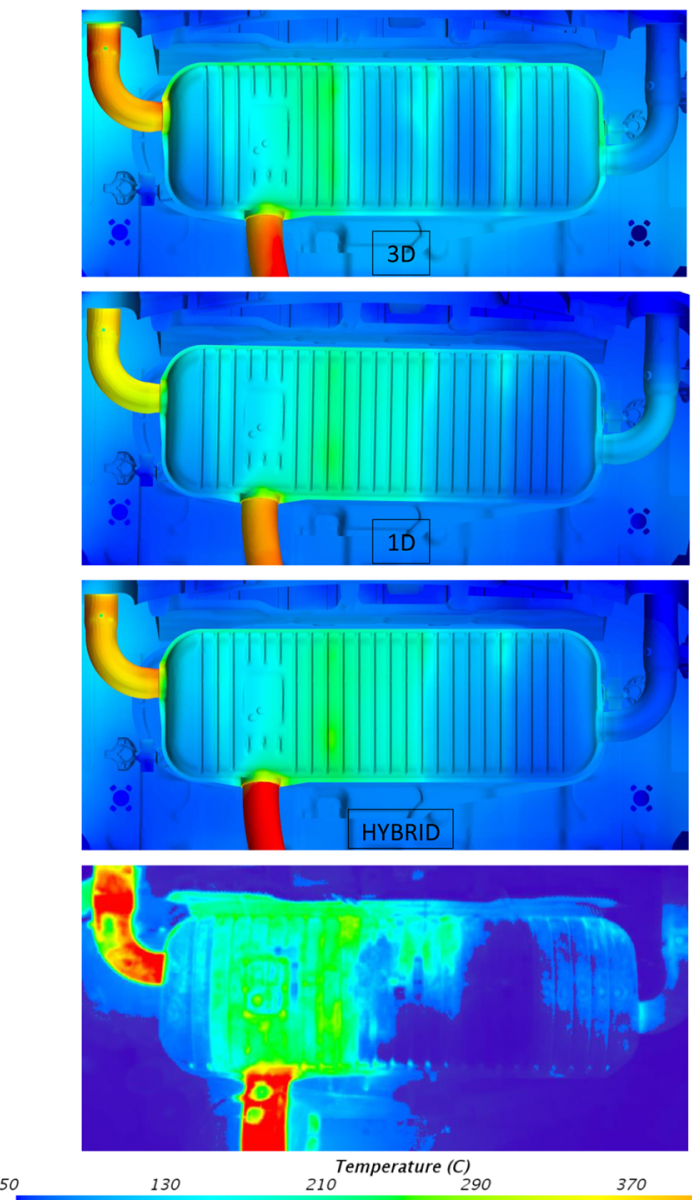

$210^{\text {Temperature }(C)}$ 370

Fig. 26 Comparison of the B60 thermography image with the 3D, 1D and Hybrid simulated surface temperature distribution on the EAS

Each methodology was given a score according to how well it fulfils each criterion, with 1 being the least match and 3 being the most well matched. In addition, each criterion was given a weight according to its priority in the decision matrix. A weight of 3 means the most important criterion and a weight of 1 means the least important. The method with the highest total would then be selected. The completely 3D model is quite straightforward to model physically as it requires pre-processing only the 3D geometry. The boundary condition setup is also relatively simple, but its requires a lot more attention to detail to capture all the effects inside of the exhaust system and this affects accuracy. This makes modelling the exhaust completely in $3 \mathrm{D}$ an overall complex affair. The completely $1 \mathrm{D}$ approach is more complicated to model physically as it requires discretising the complex internal structures of certain components into simple 1D elements. The boundary condition setup on the other hand is such that the transient effects inside the exhaust system are captured. So overall to get a good functioning system it is relatively less complex to model completely in
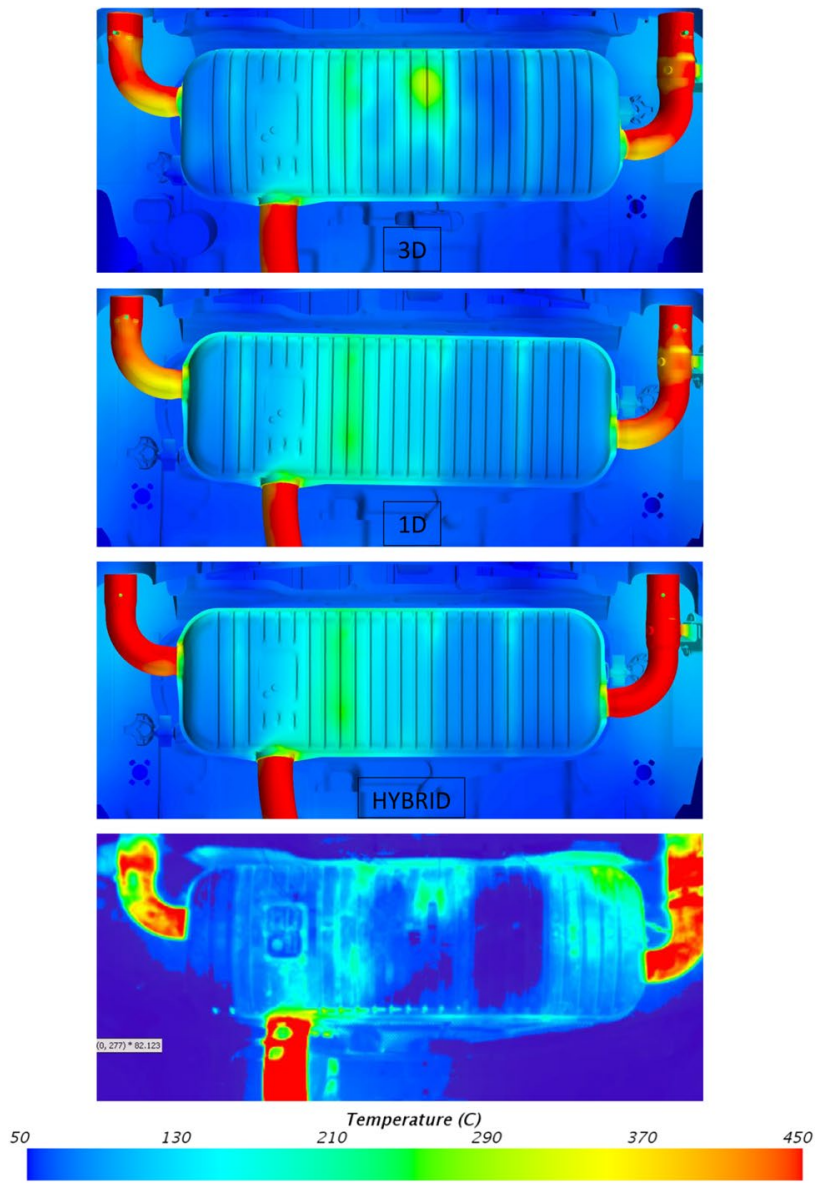

Fig. 27 Comparison of the Vmax thermography image with the 3D, 1D and Hybrid simulated surface temperature distribution on the EAS

Table 4 Decision table for exhaust methodology assessment

\begin{tabular}{lllll}
\hline Criteria methods & $\begin{array}{l}\text { Com- } \\
\text { pletely } \\
\text { 3D }\end{array}$ & $\begin{array}{l}\text { Com- } \\
\text { pletely } \\
\text { 1D }\end{array}$ & 1D/3D Hybrid & Weight \\
\hline Complexity & 1 & 3 & 2 & 1 \\
Accuracy & 2 & 1 & 3 & 3 \\
Modularity & 1 & 2 & 3 & 2 \\
Scope of application & 2 & 2 & 3 & 1 \\
Turnaround time & 2 & 3 & 2 & 2 \\
Total & 15 & 18 & 24 & \\
\hline
\end{tabular}

1D. The hybrid approach retains the ease of modelling the boundary conditions from 1D and some of the components in 3D. However, the coupling between the two codes and the modelling of complex components in $1 \mathrm{D}$ is still a bit complicated. It, therefore, scores between the other two approaches. As the results have shown, the hybrid model is more accurate than the other two modelling techniques. This is because it incorporates the spatial accuracy in the 
pipes from the 3D modelling combined with the transient effects inside the exhaust system captured by the 1D modelling. It also captures heat exchange between the wall and the exhaust gases much better than the other two approaches because of the iso-surface wall distance approach explained earlier. Modularity here pertains to the ease of modelling and testing different exhaust layouts and systems. This is a common undertaking in the early development stage of a vehicle. Testing a new layout would be easiest in the hybrid approach as it would only require a different set of pipes to be integrated and connected to the existing after-treatment components. The components themselves could be also be swapped out. This is why the hybrid approach scores higher than the other two for modularity. The scope of the hybrid approach can also be easily adapted to something like a full vehicle HVAC system simulation, where the ducts can be simulated in 3D and the cooling circuit can be simulated in 1D. Cabin comfort can also be modelled this way by modelling the cabin and the passengers in 3D while modelling the climate control system underneath the dashboard as 1D. The turnaround time for the completely 1D simulation was $10 \mathrm{~h}$ and it was $14 \mathrm{~h}$ for the completely $3 \mathrm{D}$ approach. The hybrid approach had a turnaround time of $12.5 \mathrm{~h}$. While it was faster than the completely $3 \mathrm{D}$ approach, it is not significantly faster. This is because the exchange of all the solution data between 1D and 3D slows down the process marginally. Therefore, it scores the same as the completely 3D approach on the table. After tallying all the score from Table 4, it can be seen that the method that was chosen is the $1 \mathrm{D} / 3 \mathrm{D}$ hybrid technique.

\section{Conclusion and future work}

The analysis performed in this paper shows that the 1D and 3D approaches have their benefits and drawbacks. The completely 3D approach had good spatial accuracy but lacked in the ability to easily model complex components, such as the turbocharger and catalytic converters. The fully 1D method was satisfactorily accurate for modelling the complex components; however, the spatial accuracy required for modelling the piping structure was deemed inadequate. The 1D method also has the capability of simulating fast transient effect in the exhaust system, which the fully 3D approach would struggle to simulate within an acceptable timeframe.

The hybrid approach to exhaust system simulation was an attempt to merge the positive aspects of both those methods while overcoming the shortcomings. The attempt was a successful one for the most part. Some of the drawbacks were carried over, but the hybrid method was principally effective in combining the salient features of the 1D and 3D methods. Besides that, the hybrid method also enables a modular modelling approach to exhaust system modelling.
Different exhaust system layouts and designs can be tested with relative ease.

Overall, the methodology presented in this paper serves as an effective proof of concept that a hybrid approach to exhaust system modelling can be viable alternative to the traditional modelling approaches. The method presented can also be successfully integrated into a VTM simulation workflow. However, the concept needs further work if it is to be accepted as an industry standard.

The broader scope of application of the methodology needs to be expanded to more dynamic loadcases, such as race-track and street traffic scenarios. The transferability of the method to alternative vehicle types can also be explored.

Another avenue of development would be the development of a fully transient coupling between the 1D code and the thermal solver. This would mean that the results exported from the $1 \mathrm{D}$ code would directly be used in the thermal solver as time-dependent data instead of being averaged, which would remove any errors introduced because of averaging and improve the temporal behaviour of the model. As mentioned previously, the modelling of the porous glasswool material inside the acoustic silencers is another area, where the current methodology needs improvement. The thermal properties of the material, which were empirically derived, could be experimentally identified and integrated into the model. This would improve the accuracy of the heat transfer occurring inside components, such as MAS and EAS. The TMM technique as is applied to the EAS modelling can also be improved upon by increasing the discretization of the glasswool thermal mass. However, this would increase the complexity of the EAS model.

Acknowledgements The author would like to thank Mr. Akshay Aradwad for his help in the development of the 1D simulations required for the methodology presented in this paper. The author would also like to thank Mr. Lucas Beetz from Siemens AG for all his research support and assistance in achieving the goals of this investigation.

Funding Open Access funding enabled and organized by Projekt DEAL.

Open Access This article is licensed under a Creative Commons Attribution 4.0 International License, which permits use, sharing, adaptation, distribution and reproduction in any medium or format, as long as you give appropriate credit to the original author(s) and the source, provide a link to the Creative Commons licence, and indicate if changes were made. The images or other third party material in this article are included in the article's Creative Commons licence, unless indicated otherwise in a credit line to the material. If material is not included in the article's Creative Commons licence and your intended use is not permitted by statutory regulation or exceeds the permitted use, you will need to obtain permission directly from the copyright holder. To view a copy of this licence, visit http://creativecommons.org/licenses/by/4.0/. 


\section{References}

1. Ahmed, S., Full, M., Rottengruber, H.: A new approach to model the fan in vehicle thermal management simulations. In: SAE Technical Paper Series. SAE International (2019). https://doi.org/10. 4271/2019-01-5016

2. Balakotaiah, V., Gupta, N., West, D.H.: A simplified model for analyzing catalytic reactions in short monoliths. Chem. Eng. Sci. 55(22), 5367-5383 (2000). https://doi.org/10.1016/S00092509(00)00164-0

3. Bannister, C.D., Brace, C.J., Lock, G.D., Taylor, J., Brooks, T., Fraser, N.: Experimental characterisation of heat transfer in exhaust pipe sections. SAE Int. J. Mater. Manufact. 1(1), 136-144 (2009). https://doi.org/10.4271/2008-01-0391

4. Büchner, S., Santos Lardies, S., Degen, A., Donnerstag, A., Held, W.: A modular numerical simulation tool predicting catalytic converter light-off by improved modeling of thermal management and conversion characteristics. In: SAE Technical Paper Series. SAE International (2001). https://doi.org/10.4271/2001-01-0940

5. El-Sharkawy, A., Sami, A., Hekal, A.E.R., Arora, D., Khandaker, M.: Transient modelling of vehicle exhaust surface temperature. SAE Int. J. Mater. Manufact. 9(2), 321-329 (2016). https://doi. org/10.4271/2016-01-0280

6. Enriquez-Geppert, J.: Numerische und experimentelle Analyse der Wärmeübertragung einer Abgasanlage im Gesamtfahrzeug. Phd thesis, Universität Stuttgart (2015). https://doi.org/10.18419/ OPUS-8742

7. Enriquez-Geppert, J., Wiedemann, J., Reister, H., Binner, T.: Numerical simulation of exhaust system temperatures taking into account thermal interactions with the vehicle environment. In: Vehicle thermal management systems proceedings, pp. 561-570. Woodhead Pub, Cambridge (2011). https://doi.org/10.1533/97808 57095053.7.561

8. Eroglu, S., Duman, I., Ergenc, A., Yanarocak, R.: Thermal analysis of heavy duty engine exhaust manifold using cfd. In: SAE Technical Paper Series. SAE International (2016). https://doi.org/ 10.4271/2016-01-0648

9. Fortunato, F., Caprio, M., Oliva, P., D’Aniello, G., Pantaleone, P., Andreozzi, A., Manca, O.: Numerical and experimental investigation of the thermal behavior of a complete exhaust system. In: SAE Technical Paper Series. SAE International (2007). https:// doi.org/10.4271/2007-01-1094

10. Gamma Technologies LLC: GT-Suite Flow Theory Manual, Version (2018)

11. Groppi, G., Belloli, A., Tronconi, E., Forzatti, P.: A comparison of lumped and distributed models of monolith catalytic combustors. Chem. Eng. Sci. 50(17), 2705-2715 (1995). https://doi.org/10. 1016/0009-2509(95)00099-Q

12. Groppi, G., Tronconi, E.: Theoretical analysis of mass and heat transfer in monolith catalysts with triangular channels. Chem. Eng. Sci. 52(20), 3521-3526 (1997). https://doi.org/10.1016/ S0009-2509(97)00153-X

13. Gupta, N., Balakotaiah, V.: Heat and mass transfer coefficients in catalytic monoliths. Chem. Eng. Sci. 56(16), 4771-4786 (2001). https://doi.org/10.1016/S0009-2509(01)00134-8

14. Haehndel, K.: Development of exhaust surface temperature models through the numerical prediction of $1 \mathrm{~d} / 3 \mathrm{~d}$ cfd coupling. Bachelors thesis, Royal Melbourne Institute of Technology (2010)

15. Haehndel, K.: An innovative approach to dynamic driving simulations for vehicle thermal management processes. Phd thesis, Royal Melbourne Institute of Technology (2014)

16. Haehndel, K., Frank, T., Christel, F., Abanteriba, S.: An innovative approach to race track simulations for vehicle thermal management. SAE Int. J. Passenger Cars Mech. Syst. 6(3), 1564-1576 (2013). https://doi.org/10.4271/2013-01-9121
17. Haehndel, K., Frank, T., Christel, F.M., Spengler, C., Suck, G., Abanteriba, S.: The development of exhaust surface temperature models for $3 \mathrm{~d}$ cfd vehicle thermal management simulations part 1 - general exhaust configurations. SAE Int. J. Passenger Cars Mech. Syst. 6(2), 847-858 (2013). https://doi.org/10.4271/2013-01-0879

18. Haehndel, K., Jefferies, A., Schlipf, M., Frank, T., Christel, F., Abanteriba, S.: The development of exhaust surface temperature models for $3 \mathrm{~d}$ cfd vehicle thermal management simulations part 2 - exhaust acoustic silencer configurations. In: SAE Technical Paper Series. SAE International (2014). https://doi.org/10.4271/ 2014-01-0646

19. Hayes, R.E., Kolaczkowski, S.T.: Mass and heat transfer effects in catalytic monolith reactors. Chem. Eng. Sci. 49(21), 3587-3599 (1994). https://doi.org/10.1016/0009-2509(94)00164-2

20. Hayes, R.E., Kolaczkowski, S.T.: A study of nusselt and sherwood numbers in a monolith reactor. Catal. Today 47(1-4), 295-303 (1999). https://doi.org/10.1016/S0920-5861(98)00310-1

21. Heinemann, J.: Entwicklung von Teilmodellen zur Berechnung von Oberflächentemperaturen von Abgasanlagenkomponenten. Hochschule für Technik und Wirtschaft, Berlin (2010)

22. Kandylas, I.P., Stamatelos, A.M.: Engine exhaust system design based on heat transfer computation. Energy Convers. Manage. 40(10), 1057-1072 (1999). https://doi.org/10.1016/S01968904(99)00008-4

23. Kolaczkowski, S.T.: Modelling catalytic combustion in monolith reactors-challenges faced. Catal. Today 47(1-4), 209-218 (1999). https://doi.org/10.1016/S0920-5861(98)00301-0

24. Makinde, O.D.: Modelling the thermal operation in a catalytic converter of an automobile's exhaust. In: Konaté, D. (ed.) Mathematical modeling, simulation, visualization and e-learning, pp. 51-61. Springer, Berlin (2008). https://doi.org/10.1007/ 978-3-540-74339-2_4

25. Martinez Laurent, J.C.: Transient thermal simulation process over a diesel exhaust system during regeneration. In: SAE Technical Paper Series. SAE International (2011). https://doi.org/10.4271/ 2011-01-0658

26. Meisner, S., Sorenson, S.C.: Computer simulation of intake and exhaust manifold flow and heat transfer. In: SAE Technical Paper Series. SAE International (1986). https://doi.org/10.4271/860242

27. Millo, F., Gallone, A., Mallamo, A.: Experimental and computational analysis of a tuned exhaust system for a small two-stroke engine. In: SAE Technical Paper Series. SAE International (1999). https://doi.org/10.4271/1999-01-3329

28. Moshammer, T.: Simulation of radiation effects in the presence of the exhaust system. In: SAE Technical Paper Series. SAE International (2005). https://doi.org/10.4271/2005-01-2060

29. Onorati, A., Montenegro, G., D’Errico, G., Piscaglia, F.: Integrated 1d-3d fluid dynamic simulation of a turbocharged diesel engine with complete intake and exhaust systems. In: SAE Technical Paper Series. SAE International (2010). https://doi.org/10. 4271/2010-01-1194

30. Peters, B.J., Wanker, R.J., Münzer, A., Wurzenberger, J.C.: Integrated $1 \mathrm{~d}$ to $3 \mathrm{~d}$ simulation workflow of exhaust aftertreatment devices. In: SAE Technical Paper Series. SAE International (2004). https://doi.org/10.4271/2004-01-1132

31. Schlipf, M.: Untersuchung der Durchstroemung von Nachschalldaempfern zur Erstellung eines 1d-Modelles fuer die Berechnung der Oberflaechentemperatur. Universität Stuttgart, Stuttgart (2011)

32. Sinkule, J., Hlaváček, V.: Heat and mass transfer in monolithic honeycomb catalysts-iii. Chem. Eng. Sci. 33(7), 839-845 (1978). https://doi.org/10.1016/0009-2509(78)85173-2

33. Tweddell, D., Sloss, C., Werner, T.: An advanced cfd simulation strategy for exhaust manifolds with close-coupled catalytic converters. In: SAE Technical Paper Series. SAE International (2005). https://doi.org/10.4271/2005-01-1922 
34. de Vos, S., Haehndel, K., Frank, T., Christel, F., Abanteriba, S.: The development of turbine volute surface temperature models for 3d cfd vehicle thermal management simulations: Part 3: Exhaust radial turbine volute systems. SAE Int. J. Passenger Cars Mech. Syst. 7(2), 714-727 (2014). https://doi.org/10.4271/2014-01-0648

35. Votruba, J., Mikuš, O., Nguen, K., Hlaváček, V., Skřivánek, J.: Heat and mass transfer in honeycomb catalysts-ii. Chem. Eng. Sci. 30(2), 201-206 (1975). https://doi.org/10.1016/00092509(75)80006-6

36. Votruba, J., Sinkule, J., Hlaváček, V., Skřivánek, J.: Heat and mass transfer in monolithic honeycomb catalysts-i. Chem. Eng. Sci. 30(1), 117-123 (1975). https://doi.org/10.1016/0009-2509(75) 85122-0

37. Yoshizawa, K., Mori, K., Kimura, S.: Numerical analysis of the exhaust gas flow and heat transfer in a close-coupled catalytic converter system during warm-up. In: SAE Technical Paper Series. SAE International (2001). https://doi.org/10.4271/2001-01-0943
38. Zhang, X., Romzek, M.: Computational fluid dynamics (cfd) applications in vehicle exhaust system. In: SAE Technical Paper Series. SAE International (2008). https://doi.org/10.4271/ 2008-01-0612

39. Zhang, Y., Phaneuf, K., Hanson, R., Showalter, N.: Computer modeling on exhaust system heat transfer. In: SAE Technical Paper Series. SAE International (1992). https://doi.org/10.4271/ 920262

Publisher's Note Springer Nature remains neutral with regard to jurisdictional claims in published maps and institutional affiliations. 